Reprod. Nutr. Dévelop., 1983, 23 (4), 641-677.

\title{
Déterminisme neuro humoral de l'adaptation de l'intestin résiduel après entérectomie
}

\author{
J.-P. LAPLACE
}

Laboratoire de Physiologie de la Nutrition, I.N.R.A., 78350 Jouy-en-Josas, France

Summary. Neurohumoral determinism of the adaptation of residual intestine after enterectomy.

After partial small bowel resection, compensatory hypertrophy of the residual bowel occurs. This compensation mainly results from epithelial hyperplasia, the mechanism of which is not yet fully understood. This paper reviews and compares available results, including the most recent advances. The first part of the review provides a list of the putative factors controlling epithelial cell proliferation. Intrinsic control of crypt cell proliferation by the functional villus cell compartment is mentioned as being a result of the release of chalones which are now under study. The paper then reviews extrinsic influences, i.e. nervous effects as shown by denervation, stimulation and neuromediator action or humoral effects due to endocrine and G.I. hormones. This survey does not indicate which factor(s) might be responsible for postresectional compensatory hypertrophy. The second part of the review is devoted to the role of endoluminal factors (food and secretions) of adaptation after enterectomy. The experimental basis of previous assessment of the main role of these factors is discussed and criticized; the relative importance of direct trophic action of food and secretions-known as luminal nutrition - is minimized but probable humoral mediation of compensatory hypertrophy due to the action of these factors is emphasized. The third part of the review deals with the occurrence of circulating humoral factors and the role of the nervous system in the adaptation processes. Evidence for blood-borne factors is supplied by parabiosis and cross-circulation experiments. Two humoral factors may be candidates. Enteroglucagon seems to be the humoral mediator of the main action of food and secretions. Hypophyseal hormones (possibly somathormone) must be considered as effectors of neurohumoral feedback. The role of the nervous system is established. Visceral sensitivity conveyed to the central nervous system through the vagal afferent (sensory) pathway seems to be a prerequisite to the full development of compensatory hypertrophy. It is tentatively concluded that, besides intrinsic control of epithelial renewal (chalones), two types of factor are responsible for postresectional compensatory hypertrophy: (1) enteroglucagon as the main effector of endoluminal parameters may induce some compensation; (2) neurohumoral feedback, involving visceral sensitivity through the vagus nerve and the hypothalamohypophyseal axis, would allow true adaptation as a result of the homeostatic control of functional digestive ability.

\section{Introduction.}

L'Homme et les animaux peuvent survivre après ablation (résection, entérectomie) ou exclusion fonctionnelle (court circuit, bypass) d'une partie éventuelle- 
ment importante de leur intestin grêle. Cette faculté tient au fait que l'organisme semble capable de compenser de diverses façons les déficits qui en découlent. Elle résulte aussi du fait que l'intestin grêle dispose manifestement d'une certaine réserve fonctionnelle et présente une capacité de régénération (Williamson, 1978a). Il survient en effet, après une entérectomie, divers changements (Laplace, 1975a) dont le plus remarquable est habituellement dénommé hypertrophie compensatrice de l'intestin grêle résiduel.

Cette hypertrophie, globalement enregistrée sur la base d'études morphologiques conventionnelles, est bien établie en 2 à 3 semaines et peut revêtir diverses formes selon l'espèce animale concernée, le site et l'étendue de l'entérectomie, comme en témoignent d'innombrables travaux cliniques chez l'Homme ou expérimentaux chez le Rat, le Chien, le Porc ou le Singe (voir les revues par Laplace, 1975a ; Williamson, 1978a ; Grenier et al., 1980). L'accroissement de la muqueuse de l'intestin grêle résiduel, phénomène le plus important, résulte d'une hyperplasie considérable consécutive à des modifications cinétiques et quantitatives de la production de cellules épithéliales. Cette hyperplasie de l'épithélium, établie par de multiples études (voir revue de Williamson, 1978a), est un phénomène précoce décelable dès $48 \mathrm{~h}$ après l'entérectomie (Hanson, Osborne et Sharp, 1977b ; Obertop et al., 1977 ; Oscarson et al., 1977). Enfin cette hyperplasie est l'instrument de l'augmentation de la capacité d'absorption de l'intestin résiduel et partant, d'une restauration plus ou moins complète de la capacité digestive fonctionnelle (voir revue de Laplace, 1975a). De ce fait, la compréhension des mécanismes par lesquels la croissance de la muqueuse résiduelle est stimulée pourrait conduire à d'importantes applications cliniques (Weser, 1979). Aussi, de multiples hypothèses de mécanismes peuvent être inventoriées (Tilson, 1972 ; Laplace, 1975a ; Williamson, 1978b ; Grenier et al., 1980) qui tentent d'expliquer les voies du processus d'adaptation. Si celui-ci semble concerner l'organisme entier (Laplace, 1975a et b), l'intestin résiduel en est le siège privilégié. Les progrès relativement importants, dans la compréhension des mécanismes de l'adaptation intestinale, enregistrés au cours des dernières années, nous ont incité à dresser un bilan global actualisé des connaissances en la matière.

La cible des facteurs mis en jeu étant nécessairement le renouvellement cellulaire de l'épithélium intestinal, nous exposerons dans une première partie les éléments relatifs aux facteurs de contrôle de ce renouvellement. Cet inventaire nécessaire sera délibérément limité, d'une part à ce qui concerne le seul intestin grêle, et d'autre part en raison de l'existence de plusieurs articles de synthèse spécialisés (Lipkin, 1973 ; Tutton, 1977 ; Pansu, Bérard et Lambert, 1977 ; Sassier et Bergeron, 1978 ; Lankisch, 1980 ; Balas, Senegas-Balas et Bastie, 1981). Par ailleurs, selon les auteurs, les méthodologies utilisées, voire la définition d'un certain nombre de paramètres décrivant tel ou tel aspect de la prolifération cellulaire, peuvent être fort différentes. Aussi, tout en attirant l'attention sur ce problème technique fondamental qui a fait l'objet d'une récente mise au point (AlMukhtar et al., 1982a) il n'est pas possible, dans les limites de ce mémoire, de détailler les effets enregistrés. Nous nous bornerons à noter la stimulation ou l'inhibition de la prolifération, compte tenu de notre objectif qui reste le déterminisme de l'hyperplasie après entérectomie. La seconde partie sera consacrée au 
rôle des facteurs endoluminaux dans ce déterminisme et à la médiation de leurs effets. Enfin la troisième partie établira les éléments de preuve de l'existence de facteurs systémiques et de l'intervention du système nerveux, conduisant à admettre l'existence d'un déterminisme neuro humoral complexe relevant d'une véritable régulation homéostasique.

\section{Facteurs de contrôle intrinsèques et extrinsèques du renouvellement cellulaire.}

II y a, dans les conditions physiologiques, un équilibre dynamique entre la production de cellules dans les cryptes et la desquamation de cellules mortes au sommet des villosités, de façun à assurer un renouvellement constant de l'épithélium intestinal. La multiplication dans les cryptes, la migration et la différenciation des cellules ainsi produites, seraient des caractéristiques intrinsèques, déterminées génétiquement, de l'épithélium (Sprinz, 1971). Nombre de systèmes de renouvellement cellulaire comportent un contrôle par rétroaction des cellules fonctionnelles matures sur l'activité de prolifération, contrôle intrinsèque assuré par des substances spécifiquement inhibitrices ou stimulantes selon le cas (Bullough, 1962). Aussi, le délicat équilibre du renouvellement cellılaire doit nécessairement être préservé par des mécanismes homéostasiques précis (Williamson, 1978b). Le fait qu'une isogreffe de duodénum fœtal (placée sous la capsule rénale) développe des villosités plus longues qu'une isogreffe d'iléon fœetal témoigne de la capacité de développement inhérente à chaque territoire et rend compte du gradient proximo distal de la hauteur des villosités hors de toute influence extrinsèque (Mac Donald et Ferguson, 1982). Mais cette dernière est non moins évidente lorsque des fragments de muqueuse duodénale ou iléale transplantés, donc privés des effets du milieu endoluminal, voient la hauteur de leurs villosités réduite (Mac Donald et Ferguson, 1982).

\subsection{Existence d'un contrôle de la prolifération dans les cryptes.}

Plusieurs observations convergentes conduisent à admettre l'existence d'un contrôle exercé par les cellules fonctionnelles du compartiment villositaire sur la prolifération dans les cryptes. L'état axénique se traduit par une prolifération réduite avec un allongement de la durée de migration des cellules vers la villosité (Lesher, Walburg et Sacher, 1964 ; Khoury, Floch et Hersh, 1969 ; Guenet et al., 1970 ) et une durée de vie accrue de ces cellules. La hauteur des villosités peut être modifiée en plus (Lesher, Walburg et Sacher, 1964 ; Khoury, Floch et Hersh, 1969) ou en moins (Abrams, Bauer et Sprinz, 1963 ; Meslin, Sacquet et Guenet, 1973). Cependant, toute généralisation concernant la taille des villosités doit être exclue puisque leur allongement au niveau duodénal peut coexister avec leur raccourcissement au niveau de l'iléon chez la souris axénique (Mac Donald et Ferguson, 1982). Même s'il n'est pas possible de corréler hauteur des villosités et production de cellules dans les cryptes, il reste que l'état axénique semble conduire à une durée de vie accrue des cellules villositaires, susceptible de rendre compte de la moindre prolifération dans les cryptes. L'ischémie transitoire de l'intestin grêle, qui en $2 \mathrm{~h}$ n'affecte pas les cellules des cryptes de façon irréversible 
(Wagner, 1980), conduit à une déplétion rapide du compartiment villositaire par exfoliation ; cette perte de cellules fonctionnelles provoque une forte augmentation de la prolifération dans les cryptes, localisée au segment ischémié, et culminant environ $16 \mathrm{~h}$ après le stimulus ischémique (Rijke et al., 1976; Menge et Robinson, 1979).

Les deux exemples qui précèdent concernent les effets de la modification (en plus ou en moins) de la durée de vie des cellules fonctionnelles, avec respectivement prolifération cellulaire réduite ou accrue dans les cryptes, mais le stimulus peut aussi viser directement le compartiment de prolifération. Ainsi, une irradiation corporelle totale supprime temporairement la prolifération dans les cryptes et conduit donc à une déplétion cellulaire des villosités. On enregistre lors de la récupération après l'irradiation une considèrable accélération de la prolifération dans les cryptes ; le retour à un rythme normal n'intervient qu'après restauration de la taille du compartiment villositaire fonctionnel (Galjaard, Meer-Fieggen et Giesen, 1972 ; Rijke, Meer-Fieggen et Galjaard, 1974). Une réponse analogue est enregistrée après irradiation continue (Rijke et al., 1975) unique (Potten et Hendry, 1975) ou localisée à un segment intestinal (Poulakas et Osborne, 1973).

Ces quelques éléments ne sont que les plus importants parmi ceux qui conduisent à affirmer l'existence d'un contrôle de la prolifération cellulaire par le compartiment fonctionnel. Ce mécanisme strictement local pourrait être l'instrument du maintien des caractéristiques inhérentes à chaque territoire digestif. Ce contrôle serait bien intrinsèque dans la mesure où il ne semble pas $y$ avoir intervention d'un facteur humoral systémique dans la régénération post-irradiation (Sharp et Osborne, 1981).

\subsection{Contrôle intrinsèque de la prolifération cellulaire.}

Un certain nombre de travaux ont démontré l'inhibition de la prolifération par des extraits cellulaires autologues (Tutton, 1973a; Sassier et Bergeron, 1977 ; May et al., 1979) fournissant une première base à la notion de contrôle par rétroaction des cellules villositaires sur les cellules des cryptes. L'identification des inhibiteurs endogènes des mitoses (chalones), responsables du phénomène, n'est pas à ce jour réalisée. Toutefois, May et al. (1981) ont préparé un extrait partiellement purifié de cellules des villosités d'intestin de Rat, qui inhibe de façon réversible les divisions cellulaires et la synthèse d'ADN de cellules épithéliales d'intestin de Rat en culture appartenant à une lignée continue dérivée de cellules des cryptes. La véritable spécificité de cet inhibiteur (présence dans les seules cellules des villosités, action exclusive sur la multiplication des cellules des cryptes) reste à confirmer. Au demeurant, des extraits tissulaires variés (muqueuse jéjunale, muqueuse colique, pancréas, foie, cerveau, muscle) inhibent l'incorporation de thymidine tritiée dans I'ADN de muqueuse jéjunale de cobaye en culture organotypique (Batt et Scott, 1982a). L'inhibiteur en cause paraît donc assez peu spécifique dans le cas de cette dernière expérience. L'extrait de muqueuse jéjunale perd toute activité inhibitrice après protéolyse, ce qui tend à montrer la nature polypeptidique de l'inhibiteur ; de plus, $50 \%$ de l'activité inhibitrice s'avère dialysable (Batt et Scott, 1982a) ce qui implique un poids molécu- 
laire relativement faible et en tous cas moindre que celui de l'inhibiteur décrit par May et al. (1979). Seule la caractérisation complète de l'inhibiteur en cause permettrait d'affirmer que les effets observés sont bien ceux d'une authentique chalone, à savoir spécificité cellulaire, absence de spécificité d'espèce, réversibilité, absence de cytotoxicité (Bullough, 1975). Mais, I'absence à ce jour d'isolement et de purification totale de ce type de molécules, et donc la méconnaissance de leur séquence ou formule chimique, limite la crédibilité qui peut être accordée à ce concept de chalones.

Néanmoins, si l'on admet la réalité d'un mécanisme strictement local de régulation de la taille de la muqueuse, tout phénomène d'adaptation intestinale, qui suppose le déplacement du point d'équilibre de cette régulation locale, implique une intervention extérieure pour permettre un ajustement de la taille de la muqueuse aux besoins de l'organisme (hypertrophie de lactation par exemple) et/ou à la charge de nutriments supportée par la muqueuse (cas de l'intestin résiduel après entérectomie). Cette conception rejoint la conclusion de Senior et al. (1982) qui admettent l'existence d'un mécanisme local de contrôle inhérent à l'épithélium et d'une modulation par des facteurs exogènes et endogènes en fonction des besoins de l'organisme. Indépendamment de toute interférence extérieure, les facteurs de contrôle endogènes peuvent être nerveux et/ou humoraux.

\subsection{Contrôle nerveux de la prolifération cellulaire.}

La muqueuse intestinale est richement innervée. II existe dans chaque villosité des filets nerveux sensitifs (Schofield, 1960). Des interconnexions locales nombreuses sont présentes dans le plexus sous muqueux (Feher, 1976) et les neurones intrinsèques de ce plexus sont eux-mêmes en relation avec des neurones appartenant au système vagal, comme en témoignent les images de dégénérescence observée au niveau du duodénum et du jéjunum après vagotomie cervicale bilatérale (Feher, Csanyi et Vajda, 1978). Des dégénérescences ont été constatées dans le plexus sous muqueux du duodénum après vagotomie tronculaire bilatérale chez le Porc (Missen, 1976). Par ailleurs, un réseau de filets nerveux adrénergiques a été décrit autour de la base des cryptes (Gabella et Costa, 1968 ; Costa et Gabella, 1971 ; Helme, Tutton et Wong, 1973), ainsi que des fibres acétyl-cholinestérase positives immédiatement sous-jacentes à la membrane basale des cryptes (Ahonen, 1973). Précisons qu'il s'agit toujours d'une simple " proximité » en l'absence de contact direct entre fibres nerveuses et cellules épithéliales, à la manière des axones innervant le muscle lisse intestinal qui restent largement à distance $(200 \AA$ à $1 \mathrm{~mm}$ ) des fibres musculaires lisses (Gonella, 1978). Ceci implique dans les deux cas une diffusion du neuro médiateur de la fibre nerveuse aux cellules cibles, en l'absence de toute structure synaptique.

Au-delà de ces éléments de suspicion, on dispose de diverses informations quant aux effets des dénervations, des stimulations électriques, et des neuro médiateurs sur la prolifération cellulaire. L'immuno sympathectomie allonge la durée de migration cellulaire des cryptes aux villosités (Dupont, Biggers et Sprinz, 1965). Les sympathectomies chimique (injection de 6-hydroxydopamine) 
et chirurgicale (post ganglionnaire) augmentent la durée du cycle cellulaire dans les cryptes (Tutton et Helme, 1974). Par contre, la sympathectomie préganglionnaire ne modifie pas le rythme de multiplication cellulaire (Musso et al., 1975). La vagotomie réduirait la hauteur des villosités, avec allongement transitoire du cycle cellulaire (Silen, Peloso et Jaffe, 1966) ou diminuerait passagèrement le rythme des mitoses dans les cryptes (Musso et al., 1975). Pour Lachat et Gonçalves (1978), toute dénervation autonome conduit à une diminution de l'activité mitotique, temporaire lors de sympathectomie, progressive et continue lors de parasympathectomie. A l'inverse, la stimulation électrique des nerfs mésentériques d'une anse intestinale, extériorisée en préparation aiguë, augmente le rythme des mitoses, même après sympathectomie chimique (Tutton, 1975a). La perfusion endoveineuse de noradrénaline augmente la prolifération cellulaire dans les cryptes jèjunales ; cet effet disparaît lors de blocage sélectif des récepteurs $\alpha$ (Tutton et Helme, 1974). Des cholinomimétiques ou le blocage de la dégradation de l'acétylcholine endogène conduisent également à une augmentation du rythme des mitoses dans les cryptes jéjunales'(Tutton, 1975b).

Toutes ces données, quelque peu disparates, ne sont pas convaincantes de l'existence d'un rôle physiologique direct du système nerveux intrinsèque et/ou extrinsèque dans le contrôle de la population des cellules de l'épithélium intestinal. II paraît plus vraisemblable que les diverses manœuvres évoquées ci-dessus perturbent d'une manière ou d'une autre le fragile équilibre du renouvellement sans pour autant que les voies nerveuses concernées soient nécessairement impliquées dans les conditions physiologiques. Ainsi, les hypothèses relatives à une modification de la circulation sanguine locale, basées sur des analogies avec les effets de vasoconstricteurs ou vasodilatateurs sur la prolifération cellulaire, ont été discutées par Levine, Kotler et Yezdimir (1982) sans qu'une conclusion solide puisse en être tirée. Par ailleurs, l'amoindrissement de la prolifération cellulaire après sympathectomie chimique est net chez le sujet en nutrition parentérale, mais cet effet est complètement effacé lorsque des nutriments sont normalement présents dans la lumière (Levine, Kotler et Yezdimir, 1982). Au demeurant, l'adaptation intestinale n'est pas différente chez le sujet préalablement soumis à une sympathectomie chimique (Touloukian, Tilson et Roth, 1975), et les facteurs de contrôle nerveux, s'ils existent, ne peuvent donc jouer qu'un rôle mineur.

\subsection{Contrôle humoral de la prolifération cellulaire.}

Diverses influences humorales peuvent être répertoriées, qui relèvent de l'endocrinologie générale et des effets des hormones gastro intestinales et de divers peptides régulateurs. Ne sont pas pris en compte ici les effets probables de l'acide folique et de la vitamine $B_{12}$, ou des vitamines $A$ et $D$ (Pansu, Berard et Lambert, 1977).

L'influence de l'hypophyse est reconnue depuis longtemps dans la mesure où l'hypophysectomie entraîne une atrophie rapide des muqueuses digestives (Jacobson et Magnani, 1964 ; Menge et al., 1972) avec une population cellulaire réduite dans les cryptes et un faible taux de production cellulaire (Yeh, 1977). 
L'hormone de croissance paraît jouer un rôle essentiel dans la mesure où l'injection de doses physiologiques restaure la quasi totalité des paramètres morphofonctionnels (Leblond et Carrière, 1955 ; Yeh et Moog, 1978)

Les glandes surrénales peuvent également jouer un rôle important. L'adrénaline (médullosurrénale) s'avère inhibitrice de la prolifération cellulaire par un effet de type $\beta$ adrénergique (Tutton et Helme, 1974). La surrénalectomie entraîne l'atrophie de la muqueuse (Haeger, Jacobsohn et Kahlson, 1953) et l'allongement de la durée du cycle cellulaire dans les cryptes (Tutton, 1973b). Il s'ajouterait à la réduction de la prolifération cellulaire dans les cryptes, une réduction de la hauteur des villosités selon Munday, Munday et Poat (1982) qui montrent, chez le Rat dont la libération de minéralo corticoïdes est supprimée par surcharge sodée, que l'aldostérone n'est pas en cause dans les effets de la surrénalectomie. Ceuxci semblent donc liés à la privation d'hormones glucocorticoïdes. A l'inverse, une production accrue d'hormones glucocorticoïdes, obtenue par injection d'ACTH, entraîne l'augmentation de l'index mitotique (Räsanen, 1963). L'injection de deoxycorticostérone augmente la hauteur des villosités et la vitesse de migration cellulaire (Tilson, Phillips et Wright, 1971). Toutefois, les glucocorticoïdes à forte dose freinent le renouvellement cellulaire (Lafont et Pilon, 1975). L'addition d'hydrocortisone au milieu de culture d'une lignée continue de cellules épithéliales, dérivées des cellules des cryptes d'intestin de rat, conduit à une inhibition complète de la croissance cellulaire, mais augmente la vitesse initiale de captation de divers hexoses par ces cellules sans modifier, ou peu, la captation des acides aminés (Inui et al., 1980). L'administration durant 8 jours de doses pharmacologiques de prednisolone, chez des rats soumis 3 semaines auparavant à une résection jéjunale, ne fait que stimuler diverses activités enzymatiques au niveau de la bordure en brosse sans accroître la prolifération cellulaire (Scott, Batt et Peters, 1979). Mais l'administration orale durant 4 semaines de cette même substance $\left(0,75 \mathrm{mg} \cdot \mathrm{kg}^{-1}\right)$ à des rats adultes non réséqués, conduit à une moindre prolifération cellulaire dans les cryptes avec des villosités plus courtes, mais avec préservation des activités enzymatiques et de la fonction intestinale dans son ensemble (Scott et Peters, 1982). Enfin, l'administration orale de la même dose quotidienne $\left(0,75 \mathrm{mg} \cdot \mathrm{kg}^{-1}\right)$ durant 7 jours seulement, mais à des rats soumis à une entérectomie proximale 3 semaines avant le début du traitement, conduit Batt et Scott $(1982 \mathrm{~b})$ à admettre que la prednisolone renforce la réponse adaptative en ajoutant à l'hyperplasie lexpansion de la population d'entérocytes) une hypertrophie fonctionnelle (augmentation du pouvoir fonctionnel des entérocytes).

Les hormones thyroïdiennes exercent des effets stimulants (Leblond et Carrière, 1955 ; Carrière, 1966), liés sans doute à leurs effets facilitateurs de la synthèse protéique et surtout à leur rôle potentialisateur des effets de l'hormone de croissance (Eartly et Leblond, 1954). Les hormones sexuelles seraient également stimulantes, dans la mesure où la castration réduit la taille des cryptes, tant chez le mâle (Carrière, 1966 ; Wright, Morley et Appleton, 1972) que chez la femelle (Venza-Teti, 1974).

Parmi les hormones gastro intestinales, la gastrine est actuellement considérée comme l'hormone trophique principale des muqueuses digestives (Balas, 
Senegas-Balas et Bastie, 1981). La place qui lui est reconnue est sans nul doute liée à son action sur la muqueuse gastrique, et à son rôle de pivot dans le schéma de régulation trophique proposé par Enochs et Johnson (1977). De fait, la gastrine pourrait être un relais de divers effets endocriniens ou nerveux. L'hypophysectomie réduit la gastrine antrale et fait chuter la gastrinémie ; la surrénalectomie abaisse le nombre de cellules $G$ et le taux de gastrine antrale ; le vague exerce un contrôle inhibiteur permanent de la prolifération de cellules à gastrine (Delince, Willems et De Graef, 1978). En ce qui concerne l'intestin grêle, l'administration de pentagastrine est capable de stimuler la croissance d'une population de cellules duodénales en culture (Lichtenberger et al., 1973). Des injections $\left(250 \mu \mathrm{g} \cdot \mathrm{kg}^{-1}\right)$ quotidiennes répétées durant 10 jours reproduisent chez le rat non sevré les modifications structurales de l'intestin grêle habituellement associées à une forte élévation de la gastrine antrale lors du sevrage (Lichtenberger et Johnson, 1974). La perfusion continue $\left(6 \mu \mathrm{g} \cdot \mathrm{kg}^{-1} \cdot \mathrm{h}^{-1}\right)$ de gastrine prévient I'hypoplasie intestinale observée lors de nutrition parentérale totale (Johnson et al., 1975a et b). Mais, selon Mayston, Barrowman et Dowling (1975), des injections sous cutanées quotidiennes ( $2 \mathrm{mg}$ par $100 \mathrm{~g}$ de rat) durant 15 jours n'augmentent pas la masse tissulaire jéjunale. Si les contradictions relevées peuvent être interprétées comme le fait de conditions et surtout de doses très différentes, on note que l'hypergastrinémie endogène fournit aussi des données contradictoires : accroissement de la masse intestinale (MacGregor et Way, 1976) ou hyperplasie de la muqueuse gastro duodénale mais pas de la muqueuse jejunale (Shimoda, Saunders et Rubin, 1968 ; Mansbach et al., 1968). Ceci étant, bien que l'importance de la gastrine soit moindre pour l'intestin grêle que pour l'estomac, elle peut effectivement accélérer le renouvellement cellulaire et la synthèse d'ADN in vivo.

La sécrétine exerce des effets opposés, et antagonistes de ceux de la gastrine, comme en témoigne le blocage de la synthèse d'ADN induite par la pentagastrine lors d'administration simultanée de ces 2 substances (Pansu et al., 1974 ; Johnson et Guthrie, 1974 ; Wiseman et Johnson, 1976 ; Bosshard, Pansu et Lambert, 1978). II n'existe pas à ce jour la moindre information en faveur d'un rôle trophique quelconque du polypeptide pancréatique (PP), de la motiline, du polypeptide inhibiteur gastrique (GIP) ou de la neurotensine. La cholécystokinine, trophique pour le pancréas (Petersen, Solomon et Grossman, 1978 ; Hughes et al., 1982), peut être considérée comme un agent trophique potentiel pour l'intestin grêle, un effet local de type paracrine étant possible (Bloom et Polak, 1982a).

L'entéroglucagon a été initialement mis en cause à la suite de l'observation d'une hyperplasie intestinale chez un malade affecté d'une tumeur sécrétant de l'entéroglucagon (Gleeson et al., 1971) et de la reproduction d'une hyperplasie chez le rat par injection d'extraits de cette tumeur (Dowling et Gleeson, 1973). L'analyse des profils hormonaux chez l'Homme dans diverses situations pathologiques comportant une adaptation intestinale, révèle que l'élévation du taux plasmatique d'entéroglucagon est la seule modification constamment retrouvée (Bloom et Polak, 1982a). Aussi ce peptide, qui diffère du glucagon pancréatique par son antigénicité et ses sites récepteurs, pourrait jouer un rôle important dans le contrôle du renouvellement cellulaire, sinon constituer une « hormone de 
croissance de l'intestin »(Bloom et Polak, 1982a). A l'opposé, le glucagon pancréatique réduit significativement la prolifération cellulaire (Rudo, Rosenberg et Wissler, 1976). Lors du diabète induit par la streptozotocine, une forte augmentation des synthèses d'ADN et de la prolifération cellulaire est enregistrée (Miller et al., 1977) mais cet effet positif pourrait être la conséquence de l'hyperphagie associée au diabète puisqu'une diminution de la prolifération cellulaire est constatée chez le Rat placé en alimentation égalisée sur celle des témoins (Nakayama, lju et Nakagawa, 1974).

Enfin, des substances telles que l'histamine ou la sérotonine paraissent exercer des effets opposés selon la dose : à doses faibles, toutes deux augmentent la prolifération cellulaire alors que des doses importantes ont des effets inhibiteurs (Tutton, 1974, 1976 ; Pishva et al., 1975). Mais, alors que la déplétion tissulaire en sérotonine arrête les divisions cellulaires dans les cryptes (Trendelenburg, 1963), la déplétion des tissus en histamine ne les affecte pas (Tutton, 1976).

Au total, il n'existe pas, dans cet ensemble d'informations, de données convaincantes d'un rôle privilégié de telle ou telle hormone ou substance circulante dans le contrôle du renouvellement intestinal. De toute façon, si un peptide exogène s'avère capable de stimuler, même partiellement, la réponse trophique des tissus gastro intestinaux, encore faut-il être sûr que son taux plasmatique endogène augmente effectivement au cours de l'adaptation, dans une proportion susceptible d'entraîner une réelle réponse (Johnson, 1982a). L'hypothèse (Tutton, 1977) d'un système de contrôle strictement local, fondé sur un rôle conjoint de réflexes nerveux et de la sérotonine pour réguler la taille de la muqueuse, et d'un système complémentaire intervenant pour ajuster cette taille aux besoins nutritionnels de l'organisme (par intervention du glucagon par exemple), est séduisante mais ne peut être valablement étayée. En fait, les effets répertoriés jusqu'ici peuvent n'être que la trace de perturbations induites par un stimulus non physiologique (dénervations, doses pharmacologiques). Ils peuvent aussi, pour certains d'entre eux correspondre à un rôle physiologique qui reste à démontrer. Les agents humoraux capables d'induire une hyperplasie de la muqueuse de l'intestin grêle sont assurément multiples (hormones hypophysaires, surrénaliennes ou thyroïdiennes; gastrine, cholécystokinine, entéroglucagon). II n'est donc pas possible, au travers d'un tel catalogue, d'identifier ceux d'entre eux qui pourraient être mis en jeu dans l'adaptation après entérectomie. Pour ce cas particulier, il nous faut maintenant aborder différemment l'analyse des mécanismes en cause, en gardant présent à l'esprit le rôle potentiel des divers facteurs qui viennent d'être inventoriés.

\section{Les facteurs endoluminaux de l'adaptation après entérectomie.}

Divers facteurs endoluminaux, exogènes ou endogènes, peuvent être suspectés d'exercer une influence, directe ou indirecte, sur le renouvellement cellulaire de l'épithélium intestinal, et donc d'intervenir dans le déterminisme de I'hyperplasie après entérectomie. Ce sont principalement les matériaux alimentaires exogènes, les sécrétions digestives endogènes et la flore saprophyte du tube 
digestif. Pourraient également être mis en cause certains peptides, tels que la gastrine, libérés dans la lumière gastrique voire duodénale en quantités parfois importantes (Uvnäs-Wallensten, 1977; Uvnäs-Wallensten et Efendic, 1978; Uvnäs-Wallensten et al., 1980). Leur action locale sur l'épithélium intestinal pourrait, selon le nombre, l'affinité et la localisation des récepteurs, rendre compte en toute hypothèse de certaines particularités de la réponse des divers segments digestifs à l'entérectomie. Nous n'irons pas, sur ce point, au-delà de cette remarque, en l'absence d'éléments expérimentaux répondant spécifiquement à cette question. Une influence de la flore saprophyte paraît devoir être mise hors de cause dans la mesure où la réponse adaptative de l'intestin résiduel, après résection de $70 \%$ de la longueur totale du viscère, est analogue chez le Rat conventionnel et chez le Rat axénique (Hanson, Fry et Balish, 1982). Par contre, aliments et sécrétions digestives semblent bien exercer un rôle dans le processus d'adaptation.

\subsection{Le rôle des nutriments exogènes: la nutrition endoluminale.}

L'importance du rôle des aliments présents dans la lumière digestive a été établie de longue date (Dowling et Booth, 1967 ; Gleeson, Cullen et Dowling, 1972 ; Dowling et Gleeson, 1973). Cette notion n'implique, dans sa forme initiale, que la présence des nutriments et non leur absorption dans le sang portal. Ces nutriments, au cours de leur transport à travers la muqueuse, peuvent être utilisés sur place comme source d'énergie ou comme substrat pour la synthèse cellulaire (Smyth, 1962 ; Dowling, 1967). Cet effet nutritionnel local serait susceptible d'influencer pius ou moins directement la prolifération cellulaire (Dowling et Gleeson, 1973). L'existence, le long de l'intestin grêle chez le sujet intact, d'un gradient oral-aboral décroissant de la hauteur des villosités, des teneurs en acides nucléiques et de diverses activités enzymatiques de la muqueuse, lui a parfois été attribuée (Altmann et Enesco, 1967 ; Levine et al., 1974). La nutrition endoluminale expliquerait également l'observation usuelle d'une hypertrophie de l'intestin résiduel distal, après entérectomie proximale, plus grande que celle enregistrée au niveau proximal après entérectomie distale. Le mécanisme en cause serait dans ce cas le fait de la présence au niveau distal d'un chyme plus abondant et inhabituellement riche du fait de la suppression de l'absorption en région proximale.

Divers éléments expérimentaux peuvent être reunis en faveur de cette conception. Les effets de la transposition d'un segment iléal en région jéjunale, à savoir une augmentation de la taille des villosités et de la quantité d'ADN par unité de poids de muqueuse, ont été interprétés comme résultant du contact avec un chyme plus riche tRijke, Hanson et Plaisier, 1977 ; Menge et Robinson, 1978). L'hyperphagie, qui augmente la masse d'aliments arrivant au contact de la muqueuse, est susceptible d'entraîner un accroissement de la masse tissulaire intestinale, que l'hyperphagie soit induite par l'insuline (Mac Kay, Callaway et Barnes, 1940), par l'abaissement de la température ambiante (Jacobs et al., 1975), ou qu'elle survienne du fait de la lactation (Campbell et Fell, 1964 ; Cairnie et Bentley, 1967 ; Lebas et Laplace, 1974). A l'inverse, la vacuité digestive liée au 
jeûne conduit à une atrophie structurale et fonctionnelle, rapidement réversible lors de réalimentation (Steiner et al., 1968 ; Altmann, 1972 ; Aldewachi et al., 1975 ; Hagemann et Stragand, 1977). De la même façon, l'exclusion chirurgicale d'une anse intestinale (fistule de Thiry ou de Thiry et Vella, anse en $Y$ autoévacuante), responsable d'une privation de tout contact avec les nutriments au niveau du seul segment exclu, entraîne également dans ce territoire une atrophie considérable (Laplace, 1976a) avec forte réduction du renouvellement cellulaire et de la teneur en acides nucléiques (Gleeson, Dowling et Peters, 1972 ; Gleeson, Cullen et Dowling, 1972 ; Fenyo et Hallberg, 1976a ; Williamson et al., 1978a) ou de la production de cellules par crypte et par heure (Clarke, 1974). Ces modifications sont réversibles lorsque le segment exclu est remis en circuit (Menge et al., 1973 ; Keren et al., 1975 ; Fenyo et Hallberg, 1976a). Au demeurant, la perfusion de glucose ou d'acides aminés dans une anse intestinale isolée est capable de prévenir l'hypoplasie de sa muqueuse (Menge et al., 1975b ; Jacobs, Taylor e1 Dowling, 1975).

Chez l'animal intact, une nutrition parentérale totale prolongée conduit à une atrophie globale avec doublement du rapport RNA/DNA, réduction de la prolifération cellulaire, de l'épaisseur de la muqueuse et de diverses activités enzymatiques de la bordure en brosse (Johnson et al., 1975a ; Castro et al., 1975 ; Eastwood, 1977 ; Hughes et Dowling, 1980). La réalimentation orale permet, en 48 heures seulement, une restauration partielle de la masse tissulaire et des activités enzymatiques (Hughes et Ducker, 1982). La perfusion intra gastrique de dextrose et d'acides aminés, chez des sujets soumis à nutrition parentérale totale, suffit à maintenir la masse tissulaire de l'intestin grêle (Spector, Levine et Deren, 1977).

Chez l'individu soumis à une entérectomie et alimenté par nutrition parentérale exclusive, l'adaptation morphofonctionnelle de l'intestin résiduel ne se développe pas (Feldman et al., 1976 ; Levine, Deren et Yezdimir, 1976). Si I'alimentation orale autorise le développement de l'adaptation de l'intestin résiduel, la composition du régime n'est pas indifférente. En effet, la perfusion intragastrique de triglycérides à chaîne longue permet l'adaptation après entérectomie de $50 \%$ chez le Rat ; mais ceux-ci s'avèrent plus « stimulants " que des protèines, des polysaccharides ou des triglycérides à chaîne moyenne. Une faible quantité de triglycérides à chaîne longue (20\% de l'apport énergétique total) fournie par voie intragastrique peut s'avérer aussi efficace qu'un régime standard (Morin, Grey et Garofalo, 1982).

Il semble donc bien que la présence de nutriments dans la lumière digestive soit nécessaire au développement de l'adaptation morphofonctionnelle après entérectomie (Menge et al., 1975a ; Ecknauer, Feyerabend et Raffler, 1978).

\subsection{Le rôle des sécrétions endogènes.}

Un rôle trophique des sécrétions digestives, salivaire, gastrique, dıodénale, biliaire et pancréatique, peut être suspecté au même titre que celui des nutriments pour rendre compte des effets de la transposition d'un segment distal en région proximale (Ecknauer, Clarke et Feyerabend, 1977). A l'inverse, le défaut de ces sécrétions pourrait expliquer, autant que le défaut de nutriments, l'atro- 
phie d'un segment chirurgicalement exclu de la continuité digestive (Rijke et al., 1977) ; ainsi, l'atrophie pancréatique observée en nutrition parentérale (Johnson et al., 1975a) pourrait être partiellement responsable de l'hyperplasie intestinale.

Le rôle potentiel de la sécrétion salivaire a èté récemment évoqué, en raison de l'observation d'un effet trophique à l'égard de la muqueuse gastroduodénale d'un polypeptide (" epidermal growth factor ") voisin de l'urogastrone (Gregory, 1975). Cet effet, une stimulation des synthèses d'ADN, est enregistré lors d'application endoluminale du polypeptide et paraît bien correspondre à des sites récepteurs au niveau de la surface épithéliale (Dembinski et al., 1982).

Les sécrétions gastrique et duodénale sont capables d'induire une augmentation de la taille des villosités iléales. Mais la bile et plus encore le suc pancréatique ou l'action conjuguée de ces deux sécrétions conduisent à une hyperplasie considérable des segments distaux de l'intestin grêle. Ces effets ont été bien établis depuis les travaux de Altmann et Leblond (1970) et Altmann (1971) : la transposition d'un segment duodénal dans l'iléon fait apparaître une augmentation de taille des villosités iléales en aval du transplant (rôle de la sécrétion duodénale) ; la réimplantation des canaux biliaire et pancréatique dans l'iléon conduit aussi à un accroissement des villosités, modéré sous l'influence de la bile, important dans le cas de la sécrétion pancréatique. En ce qui concerne la bile, on note que la dérivation externe totale durant 48 heures réduit la prolifération cellulaire au niveau de l'iléon, mais la perfusion duodénale continue de taurocholate de sodium chez des rats privés de bile accroît la taille des cryptes et réduit le rapport de taille crypte/villosité (Roy et al., 1975).

Les sécrétions pancréatico-biliaires conduisent aussi à une augmentation de la réponse adaptative iléale après jéjunectomie partielle (Weser, Heller et Tawil, 1977 ; Williamson et al., 1978a et b). A l'inverse, si la dérivation externe totale des sécrétions pancréatico-biliaires ne supprime pas l'hyperplasie précoce de l'iléon après jéjunectomie, elle réduit néanmoins l'importance globale de la réponse hyperplasique (Shellito et al., 1978). Cette observation implique que la présence des sécrétions pancréatico-biliaires n'a pas un caractère indispensable absolu pour le développement de l'adaptation compensatrice de l'intestin résiduel, en accord avec les conclusions de Fenyo (1977).

Cependant, les effets des sécrétions sur l'adaptation iléale après entérectomie proximale pourraient être plus complexes que ne le suggère cet ensemble de travaux. L'étude de Gelinas et Morin (1980), chez le rat soumis à une entérectomie jéjunale, montre que la dérivation des sécrétions pancréatico-biliaires dans l'iléon stimule la croissance de la muqueuse de ce territoire en l'absence de tout changement au niveau duodénal. Mais la dérivation iléale de la bile seule ou du suc pancréatique seul reste, selon les auteurs, sans effet sur la muqueuse de l'iléon. Enfin, si le suc pancréatique s'écoule normalement dans le duodénum tandis que la bile seule est dérivée vers l'iléon, une hypoplasie de la région proximale est enregistrée. Aussi, Gelinas et Morin (1980) concluent que l'association des 2 sécrétions est trophique pour l'iléon, alors qu'au niveau duodénal la bile joue un rôle protecteur de la muqueuse contre une action négative du suc pancréatique. 
La mise en œuvre récente d'un modèle différent de dérivation pancréaticobiliaire, non pas par dérivation des sécrétions vers l'intestin grêle distal, mais par transposition du jéjunum proximal entre l'estomac et le duodénum chez des rats par ailleurs non réséqués maịs alimentés soit per os soit par voie parentérale, confirme la complexité des effets des sécrétions (Miazza et al., 1982b). II y a bien dans ce cas hypertrophie de l'iléon qui reçoit plus directement les sécrétions, quel que soit le mode d'alimentation. Quoique privé des sécrétions duodénales et pancréatico-biliaires, le jéjunum transposé ne présente aucune atrophie ; il est en fait l'objet, ainsi que le duodénum, d'une hypertrophie significative en particulier lors de nutrition parentérale. Cette hypertrophie du jéjunum transposé, et de ce fait privé des sécrétions pancréatico-biliaires, tend à infirmer l'existence dans ces sécrétions d'un facteur trophique agissant directement sur l'épithélium. Mais un tel effet est cohérent avec les observations réalisées après une ligature du canal pancréatique (Senegas-Balas et al., 1981). Ceci étant, les résultats de Miazza et al. 1982b) peuvent suggérer un rôle inhibiteur des sécrétions dont la privation permettrait une hypertrophie ; mais les effets enregistrés au niveau de l'iléon ne seraient plus guère explicables que par un effet de nutrition endoluminale liè à l'apport de protéines du suc pancréatique. Or les observations lors de nutrition parentérale montrent que la nutrition endoluminale est totalement inutile à l'apparition des effets paradoxaux de ce modèle original. Si les auteurs (Miazza et al., 1982b) rejettent l'idée de la présence dans la sécrétion pancréatique d'un facteur entérotrophique spécifique, à l'encontre des notions unanimement acceptées depuis plus de dix ans, les effets enregistrés n'en restent pas moins inexpliqués. II est même suggéré que cette hyperplasie jéjunale serait responsable (par l'intermédiaire de la cholécystokinine) de l'hyperplasie pancréatique osbervée dans le même modèle et en situation de nutrition parentérale (Miazza et al., 1982c). De fait, l'existence de différences régionales dans l'adaptation à la présence des sécrétions pancréatico-biliaires, comme à la perfusion locale de glucides ou d'acides aminés dans la lumière digestive, suggère à Weser, Vandeventer et Tawil (1982) que la régulation de la croissance de la muqueuse pourrait être différente selon le segment considéré (intestin grêle proximal ou distal).

\subsection{Facteurs endoluminaux : les mécanismes en question.}

Au total, les diverses informations réunies précédemment en faveur du rôle des facteurs endoluminaux (aliments et sécrétions) dans le développement de l'hypertrophie de l'intestin résiduel peuvent se résumer comme suit : la présence $\mathrm{d}^{\prime}$ aliments dans la lumière digestive est nécessaire ; les sécrétions digestives (surtout pancréatico-biliaires) ont un effet stimulant mais non indispensable. Cependant, ce constat n'éclaire pas les mécanismes en cause : le concept de nutrition endoluminale, assez généralement admis, peut ne pas répondre totalement des effets enregistrés; de même la notion de facteur entérotrophique présent dans les sécrétions digestives, longtemps considérée comme d'évidence en dépit de la non-identification de la substance responsable, paraît devoir être remise en cause. 
Le concept de nutrition endoluminale ne permet guère de rendre compte d'une importante hypertrophie duodénale en amont d'une entérectomie jéjunale proximale (Laplace, 1975c), ni de l'hyperplasie jéjunale consécutive à une résection de I'iléon (Dowling et Booth, 1967 ; Hanson, Osborne et Sharp, 1977a et b) ou d'une adaptation iléale après colectomie (Wright et al., 1969 ; Buchholtz et al., 1976). Dans tous ces cas, la surabondance d'un chyme anormalement riche dans un territoire situé en aval du site de la résection ne peut être invoquée, puisque l'hypertrophie concerne un territoire plus proximal que celui qui a fait l'objet de la résection. Par ailleurs, dans les trois exemples considérés, aliments et sécrétions baignant normalement le segment hypertrophié, force est d'admettre l'existence d'autres facteurs agissant par une voie générale et non plus locale, sous réserve de l'hypothèse d'un rôle particulier des peptides libérés dans la lumière du tube digestif.

Alors que le rythme de production cellulaire est déjà très réduit dans une anse aveugle auto-évacuante privée de contact avec les nutriments, un jeûne de 48 h entraîne une réduction supplémentaire (Clarke, 1976). L'hypertrophie adaptative du grêle en place peut se développer, après exclusion d'un segment jéjuno iléal, que les animaux soient alimentés par voie orale ou intraveineuse (Fenyo, 1976b ; Fenyo et al., 1976) ; elle est seulement plus faible dans le second cas. Le poids de muqueuse et la teneur en ADN du grêle en place, mais aussi d'une anse exclue, sont plus élevés lors d'alimentation intragastrique que lors d'alimentation parentérale (Dworkin et al., 1976). Ces quelques faits, partiellement contradictoires avec ceux précédemment rapportés, suggèrent qu'il peut $y$ avoir intervention simultanée de facteurs locaux et généraux, avec interaction entre eux.

Les expériences de perfusion d'une solution nutritive dans une anse exclue, dont la masse muqueuse se trouve ainsi entretenue, sont suspectes dans la mesure où une stimulation de la prolifération cellulaire a aussi été obtenue par perfusion de solutions non nutritives (Clarke, 1976, 1977) en dehors de toute hypertrophie musculaire du type de celle provoquée par Fenyo (1976a). On note aussi que, chez le Lapin, des perfusions nutritives sont incapables de prévenir l'atrophie de segments exclus de la continuité digestive (Keren et al., 1975). L'étude des effets de l'administration intra gastrique de divers glucides, chez des rats par ailleurs soumis à une nutrition parentérale totale, montre une stimulation de la croissance épithéliale, que le glucide soit absorbé par transport actif ou non et qu'il soit ou non métabolisé par la paroi (Weser, Tawil et Fletcher, 1982). Ces observations ne peuvent donc étayer un rôle, nutritionnel pour l'épithélium, des aliments présents dans la lumière, dont l'action doit au moins pour une part reposer sur un autre mécanisme.

L'idée de nutrition endoluminale directe de l'épithélium sous-entend un prélèvement de matériaux tels que le glucose et les acides aminés libres. L'observation, relatée plus haut, d'une stimulation plus importante de l'hypertrophie compensatrice par les triglycérides à chaîne longue que par des protéines ou des glucides (Morin, Grey et Garofalo, 1982) implique encore un mécanisme autre que de stricte nutrition locale. Au demeurant, l'altération morpho fonctionnelle de la muqueuse de l'intestin grêle lors de déficience alimentaire en protéines conduit 
Syme et Husain (1982) à envisager aussi l'intervention conjointe de la nutrition endoluminale et d'autres facteurs, et à suggérer une "détection » de la faible teneur en protéines du milieu endoluminal.

Pour ce qui concerne l'importance des sécrétions digestives, on peut noter que la réponse adaptative du grêle résiduel ou en place, respectivement après entérectomie ou exclusion fonctionnelle, reste la même, que les sujets reçoivent un régime commercial standard ou un régime purifié qui n'entraîne qu'une stimulation minimale des diverses fonctions digestives (Touloukian, Mitruka et Hoyle, 1971; Fenyo et Hallberg, 1976b). Par ailleurs, la dérivation des sécrétions pancréatico-biliaires dans l'iléon ne peut induire une hyperplasie de ce segment distal aussi importante que celle qui résulte d'une entérectomie proximale (Williamson, 1978a). Ceci implique que même une surabondance de sécrétions déversées dans l'iléon ne peut rendre compte de la totalité de l'hypertrophie compensatrice. II est non moins évident que la présence des sécrétions, localement au contact du segment faisant l'objet de l'adaptation, n'est pas non plus une nécessité. En effet, la dérivation des sécrétions pancréatico-biliaires et duodénales directement dans le côlon n'empêche pas l'hypertrophie compensatrice de l'intestin en place après exclusion fonctionnelle (Fenyo, 1977). Une hyperplasie iléale survient encore lors d'anastomose œsophago-iléale impliquant la déviation des sécrétions dans le cæcum (Tilson, Sweeney et Wright, 1975). Ces observations conduisent à envisager, pour expliquer l'effet des aliments et des sécrétions, l'intervention d'un facteur autre que local et probablement systémique qui permettrait de mieux comprendre des résultats tels que ceux de Miazza et al. (1982b).

Il convient de noter que parallèlement à ces éléments relatifs à l'adaptation post résection, une conception analogue est envisagée pour un modèle tel que l'adaptation intestinale chez le sujet hyperphagique adapté à une ambiance froide. Ainsi Jacobs et al. (1975) expliquent l'adaptation du jéjunum par un effet de nutrition endoluminale, mais supposent l'intervention additionnelle de facteurs humoraux pour rendre compte de l'adaptation de l'iléon. Ces mêmes auteurs (Jacobs et Dowling, 1982) ont aussi, sur ce modèle d'adaptation chez le sujet hyperphagique en ambiance froide, montré que la privation de contact avec les aliments et les sécrétions (muqueuse d'une anse chirurgicalement exclue de la continuité) inhibe complètement ou partiellement la réponse adaptative, et que la dérivation des sécrétions pancréatico-biliaires par transposition proximale du jéjunum conduit à une hypertrophie jejunale analogue à celle observée par Miazza et al. (1982b).

\subsection{Vers une médiation humorale des effets des facteurs endoluminaux.}

Au total, l'influence des facteurs endoluminaux s'avère importante dans le déterminisme de l'adaptation après entérectomie. La présence d'aliments paraît être nécessaire, bien que la nutrition endoluminale de l'épithélium ne rende pas compte de l'intégralité des effets de cette présence. Les sécrétions digestives jouent au moins en partie leur rôle selon des voies probablement très différentes de ce qui était envisagé encore récemment (facteur entérotrophique d'origine 
sécrétoire). Dans un cas comme dans l'autre, les faits qui viennent d'être inventoriés tendent à montrer qu'il existe très certainement un ou d'autres facteur(s) dont la mise en jeu n'est pas moins essentielle pour assurer l'hyperplasie adaptative de l'intestin résiduel. L'existence de ces facteurs, supposés systémiques, a été admise par Clarke en 1976 après qu'il les eut considérés comme une éventualité tout à fait secondaire (Clarke, 1974).

Dès lors que l'on envisage l'idée d'une médiation humorale systémique, plus importante que l'effet trophique local de nutrition endoluminale, les hormones et peptides régulateurs gastro intestinaux doivent être mis en cause. En réalité, I'influence des aliments et celle des sécrétions sont indissociables dans la mesure où la présence des uns suscite l'excrétion des autres. S'il y a un effet local de la présence de contenus digestifs (aliments + sécrétions), les hormones ou peptides régulateurs mis en jeu pourraient exercer un effet en définitive beaucoup plus important sur le renouvellement cellulaire de l'épithélium, et surtout plus généralisé, que l'effet des contenus présents dans tel ou tel segment. Les divers mécanismes jusqu'ici suspectés doivent donc être envisagés, en accord avec Williamson et Malt (1982), comme un ensemble très intégré de facteurs trop souvent considérés comme distincts.

Ceci étant, les hormones ou peptides régulateurs pourraient agir de plusieurs façons. Une voie serait indirecte, les aliments nécessaires pour susciter leur mise en jeu stimulant les sécrétions digestives qui viendraient renforcer ou compléter l'effet des aliments. L'hypothèse d'une action indirecte a été confortée par la prévention de l'hypoplasie intestinale chez le chien en nutrition parentérale totale lors de stimulation chronique des sécrétions pancréatico-biliaires par la cholécystokinine et la sécrétine (Hughes, Bates et Dowling, 1978). Cependant, le facteur entérotrophique d'origine sécrétoire n'a jamais èté identifié, et l'analyse plus complète des effets protecteurs de l'association cholécystokinine et sécrétine conduit en fait à retenir une action directe (Hughes et al., 1982). Si l'action des hormones ou peptides régulateurs est directe au niveau des cellules des cryptes, il est envisageable qu'elle s'exerce sur le mode paracrine. Mais il est plus probable que ces substances empruntent la voie systémique.

Depuis 1979, cet ensemble d'hypothèses prévaut donc pour rendre compte de l'effet des facteurs endoluminaux et l'on admet que l'action conjointe, des nutriments au niveau local et des hormones gastro intestinales et peptides régulateurs libérés simultanément, est nécessaire au développement de l'adaptation compensatrice de l'intestin résiduel après entérectomie (Morin, Ling et Van Caillie, 1978 ; Williamson et Bauer. 1978). Encore faut-il maintenant démontrer la réalité de l'existence de facteurs systémiques et parvenir à les identifier.

\section{Les facteurs systémiques de l'adaptation après entérectomie.}

Indépendamment de la notion de médiation humorale des effets des facteurs endoluminaux, l'idée du déclenchement par l'entérectomie de la libération d'une substance circulante spécifiquement responsable de l'adaptation compensatrice a été également envisagèe de longue date. Cette hypothèse a suscité les premières 
tentatives de démonstration de l'existence d'un facteur circulant. Une telle conception a été plus particulièrement motivée par l'observation du fait que chez un sujet porteur d'une anse exclue, la résection d'une partie de l'intestin en place suscite une réponse adaptative qui compense pour partie l'atrophie préexistante de I'anse exclue (Tilson, Cleveland et Wright, 1969; Tilson et Wright, 1970; Hanson et al., 1977 ; Feldman, Carter et Grossman, 1978 ; McDermott et Roudnew, 1978). De plus, le déclenchement très précoce de la prolifération cellulaire, décelable en $48 \mathrm{~h}$ après l'entérectomie (Obertop et al., 1977), et son extension aussi bien au grêle résiduel qu'au gros intestin, plaident en faveur d'une médiation humorale de cette adaptation.

\subsection{Les preuves de l'existence d'un facteur circulant.}

Cette conception du rôle potentiel d'une substance circulante a revêtu deux formes: l'une suppose l'existence d'un inhibiteur circulant libéré par l'intestin luimême et dont le taux réduit après entérectomie autoriserait la prolifération cellulaire adaptative (Weiss et Kavanau, 1957 ; Tilson, 1972) ; l'autre suppose la libération consécutive à l'entérectomie d'une substance stimulante responsable de I'hyperplasie (Loran et Crocker, 1963; Tilson et Wright, 1970). La première de ces hypothèses d'école peut être considérée comme abandonnée et ce qui suit correspond à la recherche d'un facteur systémique stimulant. Les preuves de son existence relèvent de trois types d'expériences : transplantation hétérotopique, parabioses cutanées et parabioses vasculaires.

La transplantation de muqueuse iléale sous la capsule rénale fournit un modèle exempt de tout effet exogène direct (aliments, système nerveux) autre que celui d'un facteur circulant. Or l'entérectomie provoque une augmentation de la prolifération cellulaire des fragments transplantés (Tilson et Livstone, 1975).

Les expériences de parabiose cutanée ont été utilisées pour la première fois dans ce domaine par Loran et Carbone (1968) et méritent d'être détaillées. Chez des rats parabiotiques, l'un des 2 parabiontes subit une iléectomie $110 \%$ de la longueur de l'intestin grêle). Pour un groupe, la parabiose est établie, puis l'un des parabiontes subit l'entérectomie 30 jours plus tard, et l'étude se poursuit 30 jours supplémentaires. Dans un second groupe, la parabiose est établie 30 jours après entérectomie de l'un des sujets et l'étude se poursuit encore 30 jours. Enfin dans un troisième groupe, la parabiose est établie alors que l'un des parabiontes a été entérectomisé 30 jours auparavant, mais en plus, 30 jours après création de la parabiose, les rats sont séparés et contrôlés durant 7 jours encore. Les résultats démontrent pour tous les paramètres contrôlés une identité de réponse des deux parabiontes alors qu'un seul a été entérectomisé : augmentation du rythme de prolifération, durée de vie réduite des cellules épithéliales, rétention abrégée des cellules dans les cryptes, synchronisme accru des synthèses d'ADN. II $y$ a donc bien un stimulus humoral transmis au parabionte non opéré. II apparaît aussi que la réponse de ce dernier est identique, même si la parabiose n'est établie que 30 jours après résection du partenaire. Enfin, les résultats du troisième groupe montrent que la réponse proliférative n'est pas affectée par la séparation chirurgicale des parabiontes, alors que la réponse mito- 
tique s'efface chez le parabionte intact séparé de son partenaire opéré. Aussi Loran et Carbone (1968) concluent à l'existence de 2 facteurs dont I'un induit un changement durable et auto-entretenu de la réponse proliférative (au moins durant les 7 jours de contrôle après séparation des parabiontes), et l'autre s'avère immédiatement réversible (réponse mitotique).

La reproduction de ces résultats a été tentée selon des protocoles simplifiés. Une étude durant 2 semaines après entérectomie de l'un des sujets mis en parabiose 1 mois auparavant conduit Tilson et Wright (1971) à des résultats peu convaincants : l'augmentation $(+64 \%)$ de hauteur des villosités iléales chez l'opéré n'est pas retrouvée chez son partenaire intact ; l'accroissement du nombre de cellules bordant une villosité n'est que partiellement retrouvé $1+53 \%$ chez l'opéré ; $27 \%$ chez le partenaire intact). Kirchner et Osborne (1978) ont également réalisé des parabioses 4 jours avant ou 14 jours après résection de 80 ou $30 \%$ de l'intestin grêle mais en utilisant comme " receveur " un sujet également soumis à résection de $30 \%$ dans le but de le rendre plus « sensible ». Bien que cette dernière particularité soit acceptable en regard de l'existence d'un renforcement de la réponse après 2 résections espacées de 7 jours par rapport à l'effet d'une seule entérectomie (Wathen, Osborne et Loven, 1981), aucune influence humorale n'est mise en évidence dans ce travail (Kirchner et Osborne, 1978). Cependant, les incertitudes qui pèsent sur la qualité des échanges vasculaires dans une parabiose cutanée rendent ces contradictions insuffisantes pour rejeter définitivement les certitudes apportées par le protocole élaboré de Loran et Carbone (1968).

Pour lever ces contradictions, une technique de circulation sanguine croisée chronique, véritable parabiose vasculaire, a été développée (Laplace, 1972) chez des porcs sélectionnés au sein d'une même fratrie pour l'identité de leur groupe sanguin ( $A O$ ) et de leur système d'histocompatibilité ( $S L-A$ ). Ce type de préparation a rapidement permis de confirmer l'existence très probable d'un facteur systémique stimulant (Laplace, 1974a). Au total, 20 couples d'animaux appariés, soit dix couples de porcs intacts et dix couples comportant un porc intact et un porc soumis à jéjunectomie partielle, avec entretien permanent d'une circulation sanguine croisée durant $410 \mathrm{~h}$ en moyenne et préservation d'un niveau d'ingestion et d'une croissance corporelle normaux, ont apporté la preuve (Laplace, 1980a) de I'existence effective d'un facteur systémique circulant capable d'induire chez le partenaire non opéré une hypertrophie de l'intestin grêle.

Ces résultats recueillis chez le porc sont confirmés par la mise en cuvre d'une parabiose vasculaire chez le rat, selon la technique de Moolten et Bucher (1967), durant 48 h (Williamson, Buchholtz et Malt, 1978). Dans ce délai très court, les sujets non opérés recevant le sang d'un rat réséqué n'ont pas des teneurs en acides nucléiques différentes de leurs témoins intacts recevant le sang d'un autre rat intact. Mais ils présentent une radioactivité totale plus importante et une activité spécifique de I'ADN accrue par rapport aux témoins. Ces effets peuvent être considérés comme des signes précoces d'accroissement de la prolifération cellulaire intestinale chez les sujets intacts recevant le sang du partenaire réséqué. 
Cependant, l'interprétation des résultats obtenus chez le porc lors de circulation croisée au long cours (Laplace, 1980a) appelle quelques observations. L'une est que le partenaire intact pourrait apporter à son congénère opéré une aide nutritionnelle, en augmentant son propre niveau d'ingestion ou sa capacité digestive fonctionnelle en raison d'un déficit global en nutriments sur l'ensemble des 2 porcs. Ces hypothèses critiques, analysées en détail, ont pu être écartées (Laplace, 1980a), confirmant donc le caractère de réponse spécifique à l'entérectomie de la présence du facteur systémique, et retirant tout fondement à l'hypothèse du déclenchement de l'adaptation par une demande fonctionnelle (Tilson et Wright, 1970) interprétée comme un besoin d'absorption de nutriments supplémentaires. Une autre observation, liée à la mise en œuvre de la circulation croisée $48 \mathrm{~h}$ seulement après l'entérectomie, vient confirmer le fait déjà noté par Loran et Carbone (1968) qu'il n'est pas nécessaire pour le sujet intact d'être en contact avec l'opéré dès l'instant de l'opération ; en d'autres termes, le stimulus de libération du facteur systémique n'est pas un évènement transitoire. Enfin, la troisième observation est que si l'hypertrophie la plus intense est observée sur le jéjunum résiduel et l'iléon chez le porc réséqué, c'est au niveau duodéno jéjunal qu'est enregistrée l'hypertrophie chez le partenaire intact (Laplace, 1980a). Cette différence de localisation préférentielle des effets du facteur circulant implique une interaction avec d'autres facteurs qui pourraient bien être en première analyse les facteurs endoluminaux.

\subsection{Les agents humoraux potentie/s.}

La double certitude étant acquise de l'existence d'un facteur systémique lou d'un ensemble de facteurs) capable après entérectomie de susciter l'hyperplasie compensatrice, et de sa relative permanence dans le temps post-opératoire, la question se pose de la nature des substances en cause. II n'existe à ce jour aucun élément démonstratif du rôle privilégié d'un tacteur systémique particulier, spécifiquement libéré après une entérectomie. En fait, toutes les substances capables de stimuler la prolifération cellulaire, répertoriées dans la première partie de ce mémoire, peuvent a priori être suspectées d'un rôle particulier après entérectomie. Leur mise en jeu relève éventuellement de deux ordres de phénomènes qui ne s'excluent nullement, une médiation humorale des facteurs endoluminaux, et la libération d'un facteur humoral en réponse plus ou moins spécifique à la résection.

Les hormones gastro-intestinales et peptides régulateurs sont au premier rang des candidats pour une médiation humorale des facteurs endoluminaux. Ainsi, la gastrinémie s'avère élevée après entérectomie (surtout proximale) et de façon durable (Straus, Gerson et Yalow, 1974 ; Junghanns et al., 1975 ; Moossa et al., 1976 ; Kajiwara, Tamura et Suzuki, 1977). Mais l'hyperplasie consécutive à l'entérectomie survient après gastrectomie partielle ou totale (Hughes, Tawil et Weser, 1976 ; Tilson et Axtmayer, 1976). Elle s'avère renforcée lors d'exclusion de l'antre gastrique associée à l'entérectomie, alors que la gastrinémie est plus faible que chez le sujet soumis à entérectomie seulement (Tilson et Axtmayer, 1976). Oscarson et al. (1977) ont ensuite démontré qu'après entérectomie jéjunale, les teneurs en ARN et ADN, l'incorporation de la thymidine tritiée, la pro- 
fondeur des cryptes et la hauteur des villosités, sont indépendantes des taux de gastrine lors de variations dans un rapport de 1 à 23 de la gastrinémie endogène. Puis, Morin et Ling (1978) chez des rats soumis à une entérectomie, alimentés par voie intragastrique ou parentérale, avec ou sans perfusion continue de pentagastrine $\left(30 \mu \mathrm{g} \cdot \mathrm{kg}^{-1} \cdot \mathrm{h}^{-1}\right)$, observent que l'effet de la gastrine, limité à la partie tout à fait proxımale de l'intestin grêle, diffère dans sa localisation et son amplitude de I'hyperplasie liée à l'entérectomie et au mode d'alimentation. Enfin, complétant ces divers éléments en défaveur de la gastrine, Johnson (1982b) et Lorenz-Meyer et al. (1982) ont établi, définitivement semble-t-il, que la gastrine n'est responsable en aucune façon des changements adaptatifs intervenant au niveau de la muqueuse de l'intestin grêle.

La cholécystokinine a des effets reconnus au niveau duodénal (Johnson et Guthrie, 1976). Elle peut, associée à la sécrétine, prévenir l'hypoplasie intestinale liée à la nutrition parentérale (Hughes, Bates et Dowling, 1978) alors que ni l'une ni l'autre, utilisée séparément, n'est trophique pour l'intestin (Hughes et al., 1982). La cholécystokinine stimulerait également l'hyperplasie iléale après entérectomie, même en situation de nutrition parentérale (Weser et Tawil, 1978). Cependant, la confrontation des résultats de Hughes et al. (1982) et de Miazza et al. (1982b et $\mathrm{c}$ ), évoqués précédemment, conduit à accorder plus vraisemblablement à la cholécystokinine un rôle pancréatico-trophique. La production accrue de cholécystokinine serait une conséquence de l'hyperplasie intestinale et non une cause de celle-ci.

Reste, parmi les substances bénéficiant d'une présomption favorable, l'entéroglucagon dont la clinique a suggéré l'importance (Gleeson et al., 1971 ; Bloom et Polak 1982a). L'entéroglucagon est produit principalement au niveau de I'intestin distal, iléon et côlon (Bloom et Polak, 1982a). On conçoit ainsi que l'entérectomie distale massive puisse conduire à une chute de l'immunoréactivité plasmatique totale de type glucagon (Barros D'Sa et Buchanan, 1977). Mais hors ce cas d'iléectomie, une entérectomie massive préservant un bref segment d'iléon conduit à d'importantes modifications des cellules à entéroglucagon (Polak et al., 1982). II existe parallèlement une bonne corrélation entre l'accroissement de la prolifération cellulaire et l'élévation du taux circulant d'entéroglucagon (Al-Mukhtar et al., 1982b). II s'ajoute à cette surproduction d'entéroglucagon par l'intestin grêle résiduel, une hypertrophie fonctionnelle des cellules productrices d'entéroglucagon au niveau du côlon, avec augmentation de la concentration de ce peptide dans le tissu colique, lors d'entérectomie (Gregor et al., 1982).

Cet ensemble de données récentes fait que l'entéroglucagon apparaît comme une "hormone entérotrophique » intervenant dans l'adaptation de l'intestin résiduel après entérectomie. II existe de surcroît une relation positive entre la charge en nutriments de l'intestin distal et le taux plasmatique d'entéroglucagon (Al-Mukhtar et al., 1982b), ce qui conduit à considérer ce dernier comme le médiateur humoral des effets des facteurs endoluminaux. De fait, l'augmentation des taux plasmatiques et tissulaires d'entéroglucagon est enregistrée dans des situations diverses conduisant à l'hyperplasie : entérectomie, hyperphagie due à l'abaissement de la température ambiante, et lactation 
(Jacobs et al., 1982) ou dérivation des sécrétions pancréatico-biliaires par transposition distale du duodénum (Miazza et al., 1982a). Enfin, l'augmentation significative de la prolifération cellulaire concomitante de l'élévation du taux plasmatique d'entéroglucagon est observée chez des rats soumis à une entérectomie proximale (par rapport à des témoins soumis à une simple transsection) quel que soit leur mode ou niveau d'alimentation : orale ad libitum, hyperphagie induite par l'exposition au froid, ou nutrition parentérale (Sagor et al., 1982). On notera que, dans les mêmes situations, une hypergastrinémie n'est induite par l'entérectomie que chez les sujets alimentés ad libitum par voie orale. Ainsi toutes ces observations établissent la contemporanéité de l'augmentation du taux d'entéroglucagon et du développement de l'hyperplasie intestinale, sans cependant permettre d'établir la relation causale. Celle-ci paraît néanmoins fort vraisemblable dans la mesure où il $\mathrm{y}$ a une très étroite corrélation entre les taux croissants d'entéroglucagon (et de cholécystokinine) résultant d'entérectomies de 25, 50, 75 ou $90 \%$ de la longueur du grêle et l'augmentation du rythme de production cellulaire mesuré au niveau d'une fistule de Thiry-Vella, c'est-à-dire en dehors de toute interférence locale de la nutrition endoluminale (Gornacz et al., 1982). Cette proportionnalité des augmentations de la prolifération cellulaire et du taux plasmatique d'entéroglucagon est du reste confirmée dans diverses situations tant expérimentales que pathologiques (Bloom et Polak, 1982 b). De plus, l'entéroglucagon est capable de stimuler directement la synthèse d'ADN dans des cellules épithéliales jéjunales en culture (Uttenthal et al., 1982). L'entéroglucagon se présente donc désormais comme un candidat solide en tant que facteur humoral de l'adaptation intestinale.

La question reste par ailleurs posée de la mise en jeu d'un facteur systémique autre que l'entéroglucagon considéré comme le médiateur possible des effets des facteurs endoluminaux. Le rôle potentiel des hormones provenant de diverses glandes endocrines doit être également examiné. L'intervention des hormones sexuelles dans ce processus d'adaptation paraît peu vraisemblable. Une action de l'hypophyse antérieure, relayée par l'hormone thyroïdienne, a été suspectée (Grenier et al., 1980). Mais l'effet de cette dernière s'avère surtout lié à I'hyperphagie associée (Emde, Görge et Riecken, 1982). L'hypersécrétion de minéralocorticoïdes, en réponse aux pertes hydriques et électrolytiques dues à la résection, a été également incriminée, notamment en raison de la reproduction de I'hyperplasie iléale avec activité accrue de la Na-K-ATPase chez le rat soumis à injection de désoxycorticostérone (Tilson, Phillips et Wright, 1971). Mais cette substance minéralocorticoïde est le précurseur direct de la corticostérone à action glucocorticoïde. Or, l'hydrocortisone, corticostéroïde naturel majeur chez le Porc (Holzbauer et Newport, 1969) et de fonction typiquement glucocorticoïde, ne permet pas dans cette même espèce d'induire une quelconque hypertrophie intestinale (Laplace, 1976b). L'ACTH, qui agit plus particulièrement sur la zone fasciculée de la corticosurrénale productrice de cortisol et de corticostérone, n'entraîne chez le Porc qu'un léger accroissement de la masse tissulaire de l'intestin grêle (Laplace, 1976b) sans analogie avec l'effet d'une entérectomie, alors qu'elle affecte notablement le gros intestin. 
Reste enfin l'hormone de croissance hypophysaire, dont l'injection à doses physiologiques suffit à restaurer les caractéristiques morpho-fonctionnelles du tube digestif après hypophysectomie (Leblond et Carriere, 1955 ; Yeh et Moog, 1978). Chez le Porc, l'injection d'hormone somatotrope non spécifique (bovine), à raison de $100 \mathrm{U}$ Evans par jour et par animal de $30 \mathrm{~kg}$ pendant 10 jours, permet d'induire une augmentation de la masse de tissu intestinal reproduisant partiellement I'hypertrophie compensatrice après entérectomie (Laplace, 1974b). Par ailleurs, il a été montré (Taylor, Murphy et Dowling, 1975, 1979) que l'adaptation morphologique et fonctionnelle après entérectomie est entravée chez l'animal hypophysectomisé, et que l'hypophagie ne suffit pas à rendre compte de cet effet. Ces résultats, qui conduisent à admettre un rôle des hormones hypophysaires, sinon de l'hormone somatotrope elle-même, trouvent une confirmation dans les observations de Parhon, Petcu et Brinzoiu (1978) : augmentation du poids de l'hypophyse et signes histologiques d'hyperfonctionnement du lobe antérieur chez des rats soumis à jéjunectomie.

En définitive, la recherche des agents circulants potentiellement responsables de la médiation humorale de l'hypertrophie compensatrice après entérectomie, conduit à retenir deux possibilités dont la coexistence reste totalement plausible. D'une part, l'entéroglucagon paraît être le médiateur humoral des facteurs endoluminaux et l'instrument d'une compensation qui s'ajusterait entièrement au niveau de l'organe. D'autre part, l'hormone de croissance hypophysaire semble également susceptible de jouer le rôle déterminant que l'on peut reconnaître au facteur systémique. On conçoit aisément que le jeûne supprime la réponse adaptative assurée par l'entéroglucagon dans la mesure où les facteurs endoluminaux sont considérablement réduits dans cette situation. Mais, si les deux agents humoraux interviennent conjointement, il est moins aisé d'admettre un effet du jeûne sur la réponse adaptative qui pourrait être le fait de l'hormone somatotrope. Pourtant, le jeûne efface la réponse adaptative iléale chez des rats en parabiose (Tilson, Walton et Livstone, 1975). Dans le même sens, il est également remarquable que l'action de l'hormone somatotrope bovine enregistrée chez le porc alimenté à volonté (Laplace, 1974b) ne soit pas retrouvée chez l'animal en alimentation restreinte (Laplace, 1976b). Ces observations conduisent à admettre que la mise en œuvre d'un facteur humoral d'origine hypophysaire est également affectée d'une manière ou d'une autre par l'alimentation. Aussi, parallèlement à la compensation mise en œuvre au niveau du tube digestif lentéroglucagon), il pourrait y avoir un ajustement de la compensation au niveau général (organisme entier) par l'intervention de l'hypophyse. Un tel processus serait susceptible de rendre compte tout à la fois de l'adaptation de l'intestin résiduel et des modifications métaboliques consécutives à l'entérectomie, mais suppose la mise en jeu de mécanismes complexes d'intégration au niveau de l'axe hypothalamo-hypophysaire (Laplace, 1975a et b).

\subsection{L'intervention du système nerveux.}

Si l'on admet l'existence d'un facteur systémique déterminant d'origine hypophysaire, il faut nécessairement s'interroger sur la nature des mécanismes responsables de l'induction de sa libération lou de l'augmentation significative de 
șon taux) à la suite d'une entérectomie. Dans le cas de l'hormone somatotrope hypophysaire on peut rappeler que les mécanismes de régulation de sa sécrétion sont localisés dans l'hypothalamus médiobasal (contrôle tonique intrinsèque) avec dépendance (contrôle modulateur) vis-à-vis de l'intégrité des connections avec d'autres aires du système nerveux (Collu et al., 1973 ; Dunn et Arimura, 1974 ; Krey et al., 1975). Cela étant, le mécanisme d'information de l'hypothalamus consécutivement à l'entérectomie, supposé intervenir pour moduler une sécrétion hypophysaire, peut être de deux ordres. Un groupe d'hypothèses conduit à envisager des facteurs humoraux d'ordre métabolique et l'intervention de chémorécepteurs hypothalamiques sensibles à des variations du taux de métabolites, du fait de la réduction de capacité fonctionnelle. Un tel mécanisme correspondrait à I'hypothèse de la " demande fonctionnelle » (Tilson et Wright, 1970 ; Tilson, 1972) faisant de l'adaptation compensatrice la réponse à une sorte de faim métabolique. Aucune information expérimentale ne permet à ce jour d'étayer cette conception dans le cas de l'adaptation après entérectomie. Un autre type d'hypothèses consiste à suspecter le rôle d'afférences nerveuses apportant à l'hypothalamus, directement ou indirectement après relai dans d'autres structures, une information sensitive d'origine gastro intestinale (interoception viscérale).

Dans le sens de ce rôle possible de la sensibilité viscérale, la mise au point d'une technique de déafférentation vagale (Darcy et al., 1979 ; Laplace, 1980b) nous a permis de démontrer chez le Porc que les informations sensitives d'origine digestive empruntant la voie vagale afférente sont nécessaires au développement de l'hypertrophie compensatrice de l'intestin grêle résiduel après jéjunectomie partielle (Laplace, 1980a). La déafférentation chirurgicale, fondée sur l'existence d'une séparation anatomique des voies motrices et des voies sensitives au niveau du ganglion plexiforme chez le Porc, est par elle-même dépourvue d'effet sur le développement du tissu intestinal (Laplace, 1980a) comme sur le bilan nutritionnel (Laplace, 1981). Or, chez des porcs alimentés à volonté, et en l'absence de différence significative des niveaux moyens $d^{\prime}$ 'ingestion entre les animaux soumis à une jéjunectomie partielle et leurs congénères soumis simultanément à la même jéjunectomie et à la déafférentation vagale, on constate en moyenne l'absence quasi totale de toute hypertrophie compensatrice chez les sujets privés de sensibilité vagale (Laplace, 1980a).

Ces résultats conduisent donc à accorder un rôle considérable à un mécanisme nerveux à point de départ périphérique. Celui-ci pourrait être localisé au niveau de la riche innervation sensitive vagale de l'intestin grêle (Mei, 1978, 1981 ; El Ouazzani et Mei, 1981). On sait en effet que la sensibilité viscérale sert tout à la fois des régulations organiques du type des réflexes intervenant dans le contrôle de la motricité digestive, des régulations comportementales telles que des mécanismes de satiété (Jeanningros, 1982) et des régulations homéostasiques. La caractéristique de ces dernières est de mettre en jeu des centres supra spinaux parmi lesquels l'hypothalamus occupe une place privilégiée (Mei, 1981), dans la mesure où il reçoit d'importantes projections vagales (Jeanningros et Mei, 1980). Par ces voies, les informations afférentes aux noyaux bulbaires et relayées vers I'hypothalamus seraient susceptibles de constituer l'élément modu- 
lateur responsable en dernier ressort de la libération du facteur systémique d'origine hypophysaire ou de la libération accrue d'une hormone connue telle que l'hormone somatotrope.

II a été suggéré (Dowling, 1982) que le défaut d'hypertrophie compensatrice chez nos animaux privés de sensibilité vagale (Laplace, 1980a) pourrait résulter d'une abolition de la libération de cholécystokinine. Cette hypothèse, envisagée par analogie en raison de l'abolition de la libération de cholécystokinine (CCK-8; Maton, Selden et Chadwick, 1982) et de motiline (Svenberg et al., 1982) après administration endoveineuse d'atropine, ne peut être valablement étayée. En effet, nous avons précédemment retenu que la cholécystokinine joue sans doute un rôle pancréatico-trophique, et que l'augmentation de sa production est plus probablement une conséquence (et non une cause) de l'hyperplasie intestinale. Au demeurant, Dowling (1982) lui-même reconnaît qu'il faut, pour I'heure, admettre que l'octo-cholécystokinine est sans effet sur l'intestin, et qu'il est peu probable que la grosse molécule de cholécystokinine (CCK-33) soit trophique pour cet organe. L'éventualité d'un rôle de la cholécystokinine est donc à rejeter, même si on ignore pourquoi elle peut, associée à la sécrétine, prévenir l'hypoplasie due à une nutrition parentérale (Hughes, Bates et Dowling, 1978).

Ceci étant, l'atropinisation bloque l'action de l'acétylcholine en inhibant électivement les récepteurs cholinergiques muscariniques, c'est-à-dire qu'elle agit essentiellement en bloquant l'effet des neurones excitateurs cholinergiques des plexus intrapariétaux sur lesquels sont articulés divers neurones extrinsèques. Aussi n'est-il pas possible, en l'absence d'informations complémentaires, de conclure des effets de l'atropinisation qu'il y a blocage d'un circuit purement intrinsèque ou d'un circuit long (hypothétiquement vagal) articulé sur un neurone cholinergique intramural. II est donc encore plus hasardeux d'imaginer que la suppression des afférences sensitives vagales pourrait conduire, par interruption d'un arc réflexe long et donc modification des efférences vagales, à un changement dans la libération de tel ou tel peptide. En l'absence actuelle du moindre commencement de présomption dans le sens de l'hypothèse de Dowling (1982), et compte tenu des éléments précédemment réunis en faveur d'une intervention de I'axe hypothalamo-hypophysaire, l'abolition de l'hypertrophie compensatrice après déafférentation vagale (Laplace, 1980a) nous cònduit à considérer comme fondée l'hypothèse de l'existence d'un mécanisme neuro-hormonal, d'arc afférent nerveux (voies sensitives vagales) et d'arc efférent humoral (facteur systémique d'origine hypophysaire).

\subsection{Dualité des mécanismes d'adaptation.}

Les résultats qui précèdent font que l'influence du système nerveux tant périphérique (voies sensitives vagales) que ceptral (hypothalamus) apparaît essentielle au développement de I'hypertrophie compensatrice, dans le cadre d'un mécanisme neuro-humoral d'arc afférent nerveux et d'arc efférent humoral. Toutefois, ceci ne laisse guère de place à l'entéroglucagon considéré comme le médiateur des effets des facteurs endoluminaux. Cependant, si I'on prend en compte les variations individuelles du niveau d'ingestion pour exclure l'interférence possible de ce dernier dans l'ampleur de la compensation, telle qu'évaluée 
chez les porcs alimentés à volonté (Laplace, 1980a), l'importance du mécanisme neuro-humoral concerné doit être nuancée. Exprimée en pourcentage d'augmentation du poids de tissu sec par unité de longueur d'intestin grêle, la compensation après entérectomie est environ 4 fois plus faible chez le sujet déafférenté que chez le sujet à sensibilité viscérale intacte, soit respectivement +26 et + $96 \%$ relativement aux valeurs de référence établies chez les témoins par régression du poids de tissu sec par unité de longueur en fonction du niveau d'ingestion de matière sèche (Laplace, 1982).

Par ailleurs, la répétition de ce type d'expérience chez l'animal en situation de restriction alimentaire conduit encore à mieux cerner l'importance fonctionnelle du mécanisme neuro-hormonal (Laplace, 1982). En effet, chez l'animal ne recevant que $70 \%$ de la matière sèche ingérée par les sujets alimentés à volonté, I'hypertrophie après entérectomie est 10 fois plus faible $(+9 \%)$ que chez ces derniers $(+96 \%)$. Mais il apparaît aussi que la modeste hypertrophie consécutive à l'entérectomie chez l'animal déafférenté est analogue, que l'alimentation soit distribuée à volonté ou restreinte (respectivement +26 et $+21 \%$ ).

Ces derniers éléments suggèrent donc l'existence de deux mécanismes distincts intervenant dans l'adaptation compensatrice après entérectomie (Laplace, 1982). L'un deux, mis en évidence après déafférentation vagale, pourrait rendre compte de l'hypertrophie modérée enregistrée dans cette situation; mais si ce mécanisme est tributaire de la présence de nutriments dans la lumière digestive ou de l'ensemble des facteurs endoluminaux, il reste relativement indépendant du niveau des apports alimentaires. Le second mécanisme, apparent chez les sujets dont la sensibilité vagale est intacte, susciterait une réponse adaptative modulée, c'est-à-dire intense chez le sujet alimenté à volonté, et faible lorsque le niveau d'alimentation est réduit ; ce second mécanisme correspondrait au déterminisme neuro-humoral impliquant d'une part les afférences vagales et d'autre part l'axe hypothalamo-hypophysaire pour la mise en œuvre du facteur systémique.

\section{Conclusions.}

En l'état actuel des informations disponibles et malgré les importants progrès récemment enregistrés, nombre de points restent encore à élucider ou vérifier. Il est néanmoins possible de proposer en matière de conclusions une conception d'ensemble cohérente des mécanismes qui contrôlent l'importance de la prolifération cellulaire et assurent un ajustement de la taille de la muqueuse. Ceux-ci semblent constituer un système à trois étages :

- Au niveau du tissu lui-même, un contrôle local purement intrinsèque pourrait être assuré par l'inhibiteur provenant des cellules fonctionnelles des villosités et agissant sur les mitoses des cellules présentes dans les cryptes. Ce système constituerait donc un dispositif d'auto régulation de la taille de la muqueuse. Lorsque surviennent des perturbations, telles que celles qui découlent d'une entérectomie, d'autres mécanismes sont mis en jeu qui tous font appel à des facteurs extrinsèques. 
- Au niveau de l'organe, un mécanisme de contrôle capable d'assurer une certaine compensation repose sur l'ensemble des effets des facteurs endoluminaux (aliments et sécrétions). Beaucoup plus que par un simple effet trophique local, ces facteurs endoluminaux paraissent agir par un médiateur humoral. Celui-ci s'avère être l'entéroglucagon dont la libération est accrue du fait de la surcharge relative des territoires résiduels. Ce contrôle humoral rend probablement compte de la compensation limitée enregistrée chez les sujets déafférentés, soit un accroissement d'environ $25 \%$ du poids de tissu par unité de longueur d'intestin résiduel. Si ce mécanisme est d'évidence tributaire de la présence de digesta dans la lumière intestinale, il ne permet guère d'ajuster l'ampleur de la compensation à l'importance relative de la surcharge des segments résiduels.

- Au niveau de l'organisme entier, un troisième système de contrôle, relevant semble-t-il d'une véritable régulation homéostasique, s'ajoute aux précédents et rend compte des effets enregistrés chez le sujet non déafférenté soumis à une entérectomie. Ce système repose sur un mécanisme neuro-humoral (Laplace, 1980a, 1982) dans lequel se trouvent impliquées la sensibilité viscérale apportée au système nerveux central par voie vagale, une intégration hypothalamique et une réponse endocrinienne hypophysaire simple ou complexe. $\mathrm{Ce}$ mécanisme est particulièrement important dans la mesure où le facteur systémique, quelle qu'en soit la complexité, est indispensable pour une compensation complète (Laplace, 1982). II s'avère également important dans la mesure où il permet une modulation de la réponse adaptative entre +9 et $+96 \%$ pour une variation de $30 \%$ de la charge alimentaire, en dominant l'influence du second mécanisme qui conduit à une réponse à peu près stable $(+21$ à $+26 \%)$ pour une même variation du niveau d'alimentation (Laplace, 1982).

De fait, le mécanisme neuro-humoral paraît bien constituer un système permanent d'homéostasie par lequel l'organisme est capable d'ajuster la capacité digestive fonctionnelle à la charge usuelle de la muqueuse, perçue grâce à la sensibilité viscérale. Ce dispositif de réglage devrait en effet réagir aussi bien à une surcharge relative de l'épithélium résiduel après entérectomie qu'à une surcharge globale du fait d'une hyperphagie induite ou liée à des besoins de production. En définitive, le premier des trois dispositifs de contrôle vise l'entretien de l'état de la muqueuse ; le second permet d'assurer, après entérectomie, une certaine compensation de la perte de tissu ; mais seul le troisième constitue un véritable mécanisme d'adaptation, en ce sens qu'il permet le réajustement, après entérectomie, de la taille de l'épithélium et par là de la capacité digestive fonctionnelle, aux besoins de l'organisme.

Reçu en août 1982.

Accepté en décembre 1982.

\section{References}

ABRAMS G. D., BAUER H., SPRINZ H., 1963. Influence of the normal flora on mucosal morphology and cellular renewal in the ileum. A comparison of germ-free and conventional mice. Lab. Invest., 12, 355-364.

AHONEN A., 1973. Histochemical and electronmicroscopic observations on the development, neural control and function of Paneth cells of the mouse. Acta physiol. scand., Suppl. 398, 1-71. 
ALDEWACHI H.S., WRIGHT N. A., APPLETON D. R., WATSON A. J., 1975. The effect of starvation and refeeding on cell population kinetics in the rat small bowel mucosa. J. Anat, 119, 105-121.

AL-MUKHTAR M. Y. T., POLAK J. M., BLOOM S. R., WRIGHT N. A., 1982a. The search for appropriate measurements of proliferative and morphological status in studies on intestinal adaptation, 3-25. In ROBINSON J. W. L., DOWLING R. H., RIECKEN E. O., Mechanisms of intestinal adaptation, MTP Press Ltd, Lancaster.

AL-MUKhTAR M. Y. T., SAGOR G. R., GHATEI M. A., POLAK J. M., KOOPMANS H. S. BLOOM S. R., WRIGHT N. A., 1982b. The relationship between endogenous gastrointestinal hormones and cell proliferation in models of adaptation, 243-254. In ROBINSON J. W. L., DOWLING R. H., RIECKEN E. O., Mechanisms of intestinal adaptation, MTP Press Ltd, Lancaster.

ALTMANN G. G., 1971. Influence of bile and pancreatic secretions on the size of the intestinal villi in the rat. Am. J. Anat., 132, 167-178.

ALTMANN G. G., 1972. Influence of starvation and refeeding on mucosal size and epithelial renewal in the rat small intestine. Amer. J. Anat., 133, 391-400.

ALTMANN G. G., ENESCO M., 1967. Cell number as a measure of distribution and renewal of epithelial cells in the small intestine of growing and adult rats. Am. J. Anat., 121, 319-336.

ALTMANN G. G., LEBLOND C. P., 1970. Factors influencing villus size in the small intestine of adult rats as revealed by transposition of intestinal segments. Am. J. Anat., 127, 15-36.

BALAS D., SENEGAS-BALAS F., BASTIE M. J., 1981. Trophicité des muqueuses digestives. Reprod. Nutr. Dévelop., 21, 783-803.

BARROS D'SA A. A. B., BUCHANAN K. D., 1977. Role of gastro-intestinal hormones in the response to massive resection of the small bowel. Gut, 18, 877-881.

BATT R. M., SCOTT J., 1982a. Homeostatic control of cell proliferation in the small intestine : inhibition of DNA synthesis by an endogenous heat-stable polypeptide, 81-88. In ROBINSON J. W. L., DOWLING R. H., RIECKEN E. O., Mechanisms of intestinal adaptation, MTP Press Ltd, Lancaster.

BATT R. M., SCOTT J., 1982b. Response of the small intestinal mucosa to oral glucocorticoids, 75-88. In POLAK J. M., BLOOM S. R., WRIGHT N. A., DALY M. J., Adaptation pathophysiology of intestinal response to disease. Scand. J. Gastroenterol., 17, suppl. 74.

BLOOM S. R., POLAK J. M., 1982a. Enteroglucagon and the gut hormone profile of intestinal adaptation, 189-198. In ROBINSON J. W. L., DOWLING R. H., RIECKEN E. O., Mechanisms of intestinal adaptation, MTP Press Ltd, Lancaster.

BLOOM S. R., POLAK J. M., 1982b. The hormonal pattern of intestinal adaptation. A major role for enteroglucagon, 93-103. In POLAK J. M., BLOOM S. R., WRIGHT N. A., DALY M. J., Adaptation pathophysiology of intestinal response to disease. Scand. J. Gastroenterol., 17, suppl. 74.

BOSSHARD A., PANSU D., LAMBERT R., 1978. Action de la pentagastrine et de la sécrétine sur le renouvellement et la structure tridimensionnelle de la muqueuse jéjunale chez le rat soumis au jeûne. Gastroenterol. clin. biol., 2, 165-176.

BUCHHOLTZ T. W., MALAMUD D., ROSS J. S., MALT R. A., 1976. Onset of cell proliferation in the shortened gut : growth after subtotal colectomy. Surgery, 80, 601-607.

BULLOUGH W. S., 1962. The control of mitotic activity in adult mammalian tissues. Biol. Rev., 37, 307-342.

BULLOUGH W. S., 1975. Chalone control mechanisms. Life Sci., 16, 323-330.

CAIRNIE A. B., BENTLEY R. E., 1967. Cell proliferation studies in the intestinal epithelium of the rat. Hyperplasia during lactation. Exp. Cell Res., 46, 428-440.

CAMPBELL R. M., FELL B. F., 1964. Gastro-intestinal hypertrophy in the lactating rat and its relation to food intake. J. Physiol. (Lond.), 171, 90-97.

CARRIERE R. M., 1966. The influence of thyroid and testicular hormones on the epithelium of crypts of Lieberkuhn in the rat's intestine. Anat. Rec., 156, 423-428.

CASTRO G. A., COPELAND E. M., DUDRICK S. J., JOHNSON L. R., 1975. Intestinal disaccharidase and peroxidase activities in parenterally nourished rats. J. Nutr., 105, 776-781.

CLARKE R. M., 1974. Control of intestinal epithelial replacement : lack of evidence for a tissue specific blood-borne factor. Cell Tissue Kinet., 7, 241-250. 
CLARKE R. M., 1976. Evidence for both luminal and systemic factors in the control of rat intestinal epithelial replacement. Clin. Sci. mol. Med., 50, 139-144.

CLARKE R. M., 1977. " Luminal nutrition » versus « functional work-load " as controllers of mucosal morphology and epithelial replacement in the rat small intestine. Digestion, 15, 411-424.

COLLU R., JEQUIER J. C., LETARTE J., LEBOEUF G., DUCHARME J. R., 1973. Effect of stress and hypothalamic deafferentation on the secretion of growth hormone in the rat. Neuroendocrinology, 11, 183-190.

COSTA M., GABELLA G., 1971. Adrenergic innervation of the alimentary canal. $Z$. Zellforsch. Mikrosk. Anat., 122, 357-377.

DARCY B., FALEMPIN M., LAPLACE J. P., ROUSSEAU J. P., 1979. Importance de la voie vagale sensitive : Recherche d'une technique de déafférentation sélective chez le Porc et le Mouton. Ann. Biol. anim. Bioch. Biophys., 19, 881-888.

DELINCE P., WILLEMS G., DE GRAEF J., 1978. Antral gastrin cell proliferation after vagotomy in rats. Digestion, 18, 27-34.

DEMBINSKI A., GREGORY H., KONTUREK S. J., POLANSKI M., 1982. Trophic action of epidermal growth factor on the pancreas and gastro duodenal mucosa in rats. J. Physiol. (Lond.), 325, 35-42.

DOWLING R. H., 1967. Compensatory mechanisms in the small intestine. Brit. med. Bull., 23, 275-278.

DOWLING R. H., 1982. Small bowel adaptation and its regulation, 53-74. In POLAK J. M., BLOOM S. R., WRIGHT N. A., DALY M. J., Adaptation pathophysiology of intestinal response to disease. Scand. J. Gastroenterol., 17, suppl. 74.

DOWLING R. H., BOOTH C. C, 1967. Structural and functional changes following small intestinal resection in the rat. Clin. Sci, 32, 139-149.

DOWLING R. H., GLEESON M. H., 1973. Cell turnover following small bowel resection and bypass. Digestion, 8, 176-190.

DUNN J., ARIMURA A., 1974. Serum growth hormone levels following ablation of medial basal hypothalamus. Neuro-endocrinology, 15, 189-199.

DUPONT J. R., BIGGERS D. C., SPRINZ H., 1965. Intestinal renewal and immunosympathectomy. Arch. Pathol., 80, 357-362.

DWORKIN L. D., LEVINE G. M., FARBER N. J., SPECTOR M. H., 1976. Small intestinal mass of the rat is partially determined by indirect effects of intraluminal nutrition. Gastroenterology, 71, 626-630.

EARTLY H., LEBLOND C. P., 1954. Identification of the effects of thyroxine mediated by the hypophysis. Endocrinology, 54, 249-271.

EASTWOOD G. L., 1977. Small bowel morphology and epithelial proliferation in intravenously alimented rabbits. Surgery, 82, 613-620.

ECKNAUER R., CLARKE R. M., FEYERABEND G., 1977. An experimental model for studies on the effects of food and digestive secretions on the digestive absorptive capacity of rat small intestine. J. clin. Chem. clin. Biochem., 15, 361-366.

ECKNAUER R., FEYERABEND G., RAFFLER H., 1978. Analysis of the effects of food and of digestive secretions on the small intestine of the rat. 3) Mucosal mass, activity of brush border enzymes, and in vivo absorption of galactose, sodium and potassium. Gut, 19, 707-714.

EL OUAZZANI T., MEI N., 1981. Acido et gluco récepteurs vagaux de la région gastro-duodénale. Exp. Brain Res., 42, 442-452.

EMDE C., GÖRGE H. H., RIECKEN E. O., 1982. Is ileal hyperplasia in hyperthyroid rats caused by hyperphagia? 297-298. In ROBINSON J. W. L., DOWLING R. H., RIECKEN E. O., Mechanisms of intestinal adaptation, MTP Press Ltd, Lancaster.

ENOCHS M. R., JOHNSON L. R., 1977. Hormonal regulation of the growth of gastrointestinal tract, biochemical and physiological aspect, 3-28. In JERZY GLASS G. B. Progress in gastroenterology, vol. III, Grune and Stratton, New York.

FEHER E., 1976. Ultrastructural study of nerve terminals in the submucous plexus and mucous membrane after extirpation of the myenteric plexus. Acta anat., 94, 78-88.

FEHER E., CSANYI K., VAJDA J., 1978. Morphological changes in the small intestine of the cat following transection of the vagal nerve. Acta anat., 101, 218-224. 
FELDMAN E. J., CARTER D., GROSSMAN M. I., 1978. Intestinal adaptation : evidence for a non luminal factor which stimulates mucosal growth in dog. Gastroenterology, 74, 1033 (abstr.).

FELDMAN E. J., DOWLING R. H., Mc NAUGHTON J., PETERS T. J., 1976. Effects of oral versus intravenous nutrition on intestinal adaptation after small bowel resection in the dog. Gastroenterology, 70, 712-719.

FENYO G., 1976a. Role of mechanical stimulation in maintaining small intestinal mass in Thiry-Vella loops in the rat. Eur. Surg. Res., 8, 419-427.

FENYO G., 1976b. Morphological changes of the adapting small intestine under various conditions. An experimental and clinical study. Acta chir. scand., 142, suppl. 469, 31 p.

FENYO G., 1977. Morphological changes of the adapting small intestine deprived of gastric, duodenal, biliary and pancreatic secretions in the rat. Eur. Surg. Res., 9, 122-130.

FENYO G., HALLBERG D., 1976a. Intestinal hypertrophy after small intestinal bypass in the rat. Studies on methods and reversibility of changes. Acta. chir. scand., 142, 261-269.

FENYO G., HALLBERG D., 1976b. The influence of a chemical diet on the intestinal mucosa after jejuno-ileal bypass in the rat. Acta chir. scand., 142, 270-274.

FENYO G., HALLBERG D., SODA M., ROOS K. A., 1976. Morphological changes in the small intestine following jejuno ileal shunt in parenterally fed rats. Scand. J. Gastroenterol., 11. $635-640$

GABELLA G., COSTA M., 1968. Adrenergic fibres in the mucous membrane of guinea-pig alimentary tract. Experientia, 24, 706-707.

GALJAARD H., MEER-FIEGGEN Van der W., GIESEN J., 1972. Feedback control by functional villus cells on cell proliferation and maturation in intestinal epithelium. Exp. Cell Res., 73, 197207.

GELINAS M. D., MORIN C. L., 1980. Effects of bile and pancreatic secretions on intestinal mucosa after proximal small bowel resection in rats. Can. J. Physiol. Pharmacol., 58, 1117-1123.

GLEESON M. H., BLOOM S. R., POLAK J. M., HENRY K., DOWLING R. H., 1971. Endocrine tumour in kidney affecting small bowel structure, motility and absorptive function. Gut, 12, 773-782.

GLEESON M. H., CULLEN J., DOWLING R. H., 1972. Intestinal structure and function after small bowel bypass in the rat. Clin. Sci, 43, 731-742.

GLEESON M. H., DOWLING R. H., PETERS T. J., 1972. Biochemical changes in intestinal mucosa after experimental small bowel bypass in the rat. Clin. Sci., 43, 743-757.

GONELLA J., 1978. La motricité digestive et sa régulation nerveuse. J. Physiol. (Paris), 74, $131-140$. GORNACZ G. E., GHATEI M. A., AL-MUKHTAR M. Y. T., YEATS Y. C., ADRIAN T. E., WRIGHT N. A., BLOOM S. R., 1982. Circulating enteroglucagon and CCK levels correlate with enterocyte production rate in defunctioned bowel in the rat (abstr.), p. 27, 4th int. Symp. Gastrointestinal hormones, Stockholm, June 20-23.

GREGOR M., BRYANT M. G., BUCHAN A. M. J., POLAK J. M., BLOOM S. R., 1982. Effect of intestinal resection of colonic regulatory peptides in the rat, 549-554. In ROBINSON J. W. L., DOWLING R. H., RIECKEN E. O., Mechanisms of intestinal adaptation, MTP Press Ltd, Lancaster.

GREGORY H., 1975. Isolation and structure of urogastrone and its relationship to epidermal growth factor. Nature, 257, 325-327.

GRENIER J. F., MARESCAUX J., STOCK C., SAVA G., COURSIMAULT B., 1980. Bases physiopathologiques de l'adaptation intestinale après entérectomie. Ann. Gastroentérol. Hépatol., 16. 163-168.

GUENET J. L., SACQUET E., GUENEAU G., MESLIN J. C., 1970. Action de la micro-flore totale du rat sur l'activité mitotique des cryptes de Lieberkühn, C. R. Acad. Sci., Paris, 270 D. 30873090.

HAEGER K., JACOBSOHN D., KAHLSON G., 1953. Atrophy of gastrointestinal mucosa following hypophysectomy or adrenalectomy. Acta physiol. scand., supp/. 111, 161-169.

HAGEMANN R. F., STRAGAND J. J., 1977. Fasting and refeeding : cell kinetic response of jejunum, ileum and colon. Cell Tissue Kinet., 10, 3-14.

HANSON W. R., FRY R. J. M., BALISH E., 1982. Intestinal adaptation in germ-free rats following resection, 353-359. In ROBINSON J. W. L., DOWLING R. H., RIECKEN E. O., Mechanisms of intestinal adaptation, MTP Press Ltd, Lancaster. 
HANSON W. R., OSBORNE J. W., SHARP J. G., 1977a. Compensation by the residual intestine, after intestinal resection in the rat. 1) Influence of amount of tissue removed. Gastroenterology, 72, 692-700.

HANSON W. R., OSBORNE J. W., SHARP J. G., 1977b. Compensation by the residual intestine after intestinal resection in the rat. 2) Influence of post operative time interval. Gastroenterology, 72, 701-705.

HANSON W. R., RIJKE R. P. C., PLAISIER H. M., VAN EWIJK W., OSBORNE J. W., 1977. The effect of intestinal resection on Thiry Vella fistulae of jejunal and ileal origin in the rat: Evidence for a systemic control mechanism of cell renewal. Cell. Tissue Kinet., 10, 543-555.

HELME R. D., TUTTON P. J. M., WONG W. C., 1973. The role of catecholamines in the regulation of crypt cell proliferation. 2) Sympathectomy. J. Anat., 116, 468 (Abstr.).

HOLZBAUER M., NEWPORT H. M., 1969. Adrenal secretion rates and adrenal tissue concentrations of pregnenolone, progesterone, $11 \beta \mathrm{OH}$ androstenedione, and some other steroids in young pigs and dogs. J. Physiol. (Lond.), 200, 821-848.

HUGHES C. A., BATES T., DOWLING R. H., 1978. Cholecystokinin and secretin prevent the intestinal mucosal hypoplasia of total parenteral nutrition in the dog. Gastroenterology, 75, 3441.

HUGHES C. A., BREUER R. S., DUCKER D. A., HATOFF D. E., DOWLING R. H., 1982. The effect of cholecystokinin and secretin on intestinal and pancreatic structure and function, 435-450. In ROBINSON J. W. L., DOWLING R. H., RIECKEN E. O., Mechanisms of intestinal adaptation, MTP Press Ltd, Lancaster.

HUGHES C. A., DOWLING R. H., 1980. Speed of onset of adaptive mucosal hypoplasia and hypofunction in the intestine of parenterally fed rats. Clin. Sci., 59, 317-327.

HUGHES C. A., DUCKER D. A., 1982. The effect of enteral nutrition on the gut and pancreas after total parenteral nutrition, 173-174. In ROBINSON J. W. L., DOWLING R. H., RIECKEN E. O., Mechanisms of intestinal adaptation, MTP Press Ltd, Lancaster.

HUGHES W., TAWIL T., WESER E., 1976. Effect of antrectomy on ileal hyperplasia after jejunectomy in the rat. Clin. Res., 24, 286 (abstr.).

INUI K. I., QUARONI A., TILLOTSON L. G., ISSELBACHER K., 1980. Aminoacid and hexose transport by cultured crypt cells from rat small intestine. Am. J. Physiol., 239, C190-C196.

JACOBS L. R., BLOOM S., HARSOULIS P., DOWLING R. H., 1975. Intestinal adaptation in hypothermic hyperphagia. Clin. Sci. mol. Med., 48, 14 P (abstr.).

JACOBS L. R., DOWLING R. H., 1982. Relative roles of luminal nutrition and pancreaticobiliary secretions in regulating intestinal growth and function in the cold- acclimated rat, 433-434. In ROBINSON J. W. L., DOWLING R. H., RIECKEN E. O., Mechanisms of intestinal adaptation, MTP Press Ltd, Lancaster.

JACOBS L. R., POLAK J. M., BLOOM S. R., DOWLING R. H., 1982. Intestinal mucosal and fasting plasma levels of immunoreactive enteroglucagon in three models of intestinal adaptation: resection, hypothermic hyperphagia and lactation in the rat, 231-240. In ROBINSON J. W. L., DOWLING R. H., RIECKEN E. O., Mechanisms of intestinal adaptation, MTP Press Ltd, Lancaster.

JACOBS L. P., TAYLOR B. R., DOWLING H. R., 1975. Effect of luminal nutrition on the intestinal adaptation following Thiry-Vella bypass in the dog. Clin. Sci. mol. Med., 49, 26 P (abstr).

JACOBSON E. D., MAGNANI T. J., 1964. Some effects of hypophysectomy on gastrointestinal functions and structure. Gut, 5, 473-479.

JEANNINGROS R., 1982. Vagal unitary responses to intestinal aminoacid infusions in the anesthetized cat : a putative signal for protein induced satiety. Physiol. Behav., 28, 9-21.

JEANNINGROS R., MEI N., 1980. Vagal and splanchnic effects at the level of the ventro median nucleus of the hypothalamus in the cat. Brain Res., 185, 239-251.

JOHNSON L. R., 1982a. Effect of exogenous gut hormones on gastrointestinal mucosal growth, 89-92. In POLAK J. M., BLOOM S. R., WRIGHT N. A., DALY M. J., Adaptation pathophysiology of intestinal response to disease. Scand. J. Gastroenterol., 17, suppl. 74.

JOHNSON L. R., 1982b. Role of gastrointestinal peptides in intestinal adaptation, 201-211. In ROBINSON J. W. L., DOWLING R. H., RIECKEN E. O., Mechanisms of intestinal adaptation, MTP Press Ltd, Lancaster.

JOHNSON L. R., COPELAND E. M., DUDRICK S. J., LICHTENBERGER L. M., CASTRO G. A., 1975a. Structural and hormonal alterations in the gastrointestinal tract of parenterally fed rats. Gastroenterology, 68, 1177-1183.

JOHNSON L. R., GUTHRIE P. D., 1974. Secretin inhibition of gastrin-stimulated deoxyribonucleic acid synthesis. Gastroenterology, 67, 601-606.

JOHNSON L. R., GUTHRIE P., 1976. Effect of cholecystokinin and 16, 16-dimethyl prostaglandin $t_{2}$ on RNA and DNA of gastric and duodenal mucosa. Gastroenterology, 70, 59-65. 
JOHNSON L. R., LICHTENBERGER L. M., COPELAND E. M., DUDRICK S. J., CASTRO G. A., 1975b. Action of gastrin on gastrointestinal structure and function. Gastroenterology, 68, 1184-1192.

JUNGHANNS K., KAESS H., DÖRNER M., ENCKE A., 1975. The influence of resection of the small intestine on gastrin levels. Surg. Gynec. Obstet., 140, 27-29.

KAJIWARA T., TAMURA K., SUZUKI T., 1977. Follow-up study of gastrin response after resection of the jejunum and the ileum. Ann. Surg., 186, 694-699.

KEREN D. F., ELLIOTT H. L., BROWN G. D., YARDLEY J. H., 1975. Atrophy of villi with hypertrophy and hyperplasia of Paneth cells in isolated (Thiry-Vella) ileal loops in rabbits. Light microscopic studies. Gastroenterology, 68, 83-93.

KHOURY K. A., FLOCH M. H., HERSH T., 1969. Small intestinal mucosal cell proliferation and bacterial flora in the conventionalisation of the germ-free mouse. J. exp. Med., 130, 659-670.

KIRCHNER F. R., OSBORNE J. W., 1978. Failure to find a humoral factor which influences the compensatory response after resection of the rat small bowel. Cell Tissue Kinet., 11, 227-234.

KREY L. C., LU K. H., BUTLER W. R., HOTCHKISS J., PIVA F., KNOBIL E., 1975. Surgical disconnection of the medial basal hypothalamus and pituitary function in the rhesus monkey. 2) G. H. and cortisol secretion. Endocrinology, 96, 1088-1093.

LACHAT J. J., GONÇALVES R. P., 1978. Influence of autonomic denervation upon the kinetics of the ileal epithelium of the rat. Cell Tissue Res., 192, 285-297.

LAFONT J., PILON R., 1975 . Influence of glucocorticoids on some morphological and biochemical aspects of rat small intestinal mucosa. Biochim. biophys. Acta, 392, 288-298.

LANKISCH P. G., 1980. Trophic effects of gastrointestinal hormones. Clin. Gastroenterol., 9, 773-784.

LAPLACE J. P., 1972. Circulation sanguine croisée chronique chez le Porc : Technique chirurgicale, entretien, validité. J. Physiol. (Paris), 64, 165-172.

LAPLACE J. P., 1974a. Intestinal resection in chronically blood-crossed twin pigs : blood-carried factor (s). Digestion, 10, 229 (abstr.).

LAPLACE J. P., 1974b. Does growth hormone somewhat reproduce partial small bowel resection effects, 1-5. 3rd int. Pig Vet. Soc. Congr., Lyon, L 20.

LAPLACE J. P., 1975a. Small bowel resections : Exhaustive approach to a theory of adaptation. World Rev. Nutr. Diet., 23, 1-224.

LAPLACE J. P., 1975b. D'une théorie générale des processus d'adaptation au cas particulier de l'entérectomie. Résultats élémentaires obtenus chez le Porc. In Réanimation entérale à faible débit continu. Coll. INSERM, 53, 75-88.

LAPLACE J. P., 1975c. Somatic and visceral growth, and adiposity in the pig after partial small bowel resection. 1) Variations according to the kinds of operations, to the specific location along the intestinal tract and to the sex of the animals. Ann. Rech. vét., 6, 265-288.

LAPLACE J. P., 1976a. Résection intestinale chez le Porc : 3) Effets comparés de la résection ou de l'exclusion fonctionnelle d'un segment jéjunal selon l'âge et le sexe. Ann. Zootech., 25, 485503.

LAPLACE J. P., 1976b. Conséquences de la réduction de la capacité digestive fonctionnelle chez le Porc. Th. Doct. Sci. nat., Université Paris XI (Orsay), $130 \mathrm{pp}$.

LAPLACE J. P., 1980a. Compensatory hypertrophy of the residual small intestine after partial enterectomy. A neurohumoral feedback? Ann. Rech. vét., 11, 165-177.

LAPLACE J. P., 1980b. Surgical deprivation of vagal afferences from the gastrointestinal tract of the pig: clinical and EMG studies, 145-152. In CHRISTENSEN J., Gastrointestinal motility. Raven Press, New York.

LAPLACE J. P., 1981. Enterectomy, vagal deafferentation and nutrient utilization in the pig. Ann. Zootech., 30, 465-470.

LAPLACE J. P., 1982. Impairment by vagal deafferentation of the compensatory hypertrophy after enterectomy, at high and low feeding levels, 321-331. In ROBINSON J. W. L., DOWLING R. H., RIECKEN E. O., Mechanisms of intestinal adaptation, MTP Press Ltd, Lancaster.

LEBAS F., LAPLACE J. P., 1974. Mensurations viscérales chez le Lapin. 3) Variations chez la femelle au cours d'un cycle de reproduction en fonction du niveau d'alimentation durant la gestation. Ann. Zootech., 23, 267-292.

LEBLOND C. P., CARRIERE R., 1955. The effect of growth hormone and thyroxine on the mitotic rate of the intestinal mucosa of the rat. Endocrinology, 56, 261-266. 
LESHER S., WALBURG H. E., SACHER G. A., 1964. Generation cycle in the duodenal crypt cells of germ free and conventional mice. Nature (Lond.), 202, 884-886.

LEVINE G. M., DEREN J. J., STEIGER E., ZINNO R., 1974. Role of oral intake in maintenance of gut mass and disaccharidase activity. Gastroenterology, 67, 975-982.

LEVINE G. M., DEREN J. J., YEZDIMIR E., 1976. Small-bowel resection : Oral intake is the stimulus for hyperplasia. Am. J. Dig. Dis., 21, 542-546.

LEVINE G. M. KOTLER D. P., YEZDIMIR E. A., 1982. Luminal nutrition obviates sympathectomyinduced intestinal atrophy, 311-317. In ROBINSON J. W. L., DOWLING R. H., RIECKEN E. O., Mechanisms of intestinal adaptation, MTP Press Ltd, Lancaster.

LICHTENBERGER L., JOHNSON L. R., 1974. Gastrin in the ontogenic development of the small intestine. Am. J. Physiol., 227, 390-395.

LICHTENBERGER L., MILLER L. R., ERWIN D. N., JOHNSON L. R., 1973. Effect of pentagastrin on adult rat duodenal cells in culture. Gastroenterology, 65, 242-251.

LIPKIN M., 1973. Proliferation and differentiation of gastro intestinal cells. Physiol. Rev., 53, 891915.

LORAN M. R., CARBONE J. V., 1968. The humoral effect of intestinal resection on cellular proliferation and maturation in parabiotic rats, 127-138. In SULLIVAN M. F., Gastrointestinal radiation injury. Excerpta med. Found. Ed., Amsterdam.

LORAN M. R., CROCKER T. T., 1963. Population dynamics of intestinal epithelia in the rat two months after partial resection of the ileum. J. Cell Biol., 19, 285-291.

LORENZ-MEYER H., VÖLKER J. A., FRIEDEL N., SCHEUER A., 1982. Investigations of the trophic action of gastrin and cholecystokinin on structure and function of the rat jejunal mucosa, 227230. In ROBINSON J. W. L., DOWLING R. H., RIECKEN E. O., Mechanisms of intestinal adaptation, MTP Press Ltd, Lancaster.

MAC DONALD T. T., FERGUSON A., 1982. Regulation of villus height : the role of luminal factors in determining the villus height gradient of the mouse small intestine, 47-53. In ROBINSON J. W. L., DOWLING R. H., RIECKEN E. O., Mechanisms of intestinal adaptation, MTP Press Ltd, Lancaster.

MAC GREGOR I. L., WAY L. W., 1976. Chronic hypergastrinemia produces hypertrophy of the liver and intestine in rats. Surg. Forum 27, 411-413.

MAC KAY E. M., CALLAWAY J. W., BARNES R. H., 1940. Hyper alimentation in normal animals produced by protamine insulin. $J$. Nutr., 20, 59-66.

MANSBACH C. M., WILKINS R. M., DOBBINS W. O., TYOR M. P., DURHAM N. C., 1968. Intestinal mucosal function and structure in the steatorrhea of Zollinger Ellison syndrome. Arch. int. Med., 121, 487-494.

MATON P. N., SELDEN A. C., CHADWICK V. S., 1982. Measurement of plasma cholecystokinins (CCKS) using high pressure liquid chromatography (HPLC) and radioimmunoassay (RIA) : response to oral fat and effect of atropine. Regul. Peptides, 3, 76 (abstr.).

MAY R. J., QUARONI A., KIRSCH K., ISSELBACHER K. J., 1979. A specific inhibitor of intestinal cell proliferation : isolation from rat intestinal villous cells. Gastroenterology, 76, 1196 (abstr.).

MAY R. J., QUARONI A., KIRSCH K., ISSELBACHER K. J., 1981. A villous cell-derived inhibitor of intestinal cell proliferation. Am. J. Physiol., 241, G520-G527.

MAYSTON P. D., BARROWMAN J. A., DOWLING R. H., 1975. Effect of pentagastrin on small bowel structure and function in the rat. Digestion, 12, 78-84.

MCDERMOTT F., ROUDNEW B., 1978. Epithelial cell population kinetics of isolated ileal loops (Thiry Vella fistulae) after $40 \%$ small intestinal resection. Virchows Arch., 28B, 179-185.

MEI N., 1978. Vagal glucoreceptors in the small intestine of the cat. J. Physiol. (Lond.), 282, 485-506.

MEI N., 1981. La sensibilité viscérale. J. Physiol. (Paris), 77, 597-612.

MENGE H., BLOCH R., LORENZ-MEYER H., RIECKEN E. O., 1973. Morphologie und Funktion isoperistaltischer ausgeschalteter Jejunalschlingen nach Ruckverlegung in die Dünndarmpassage. Res. exp. Med., 161, 133-140.

MENGE H., BLOCH R., WARM K., LORENZ-MEYER H., RIECKEN E. O., 1972. Der Einfluss einer Hypophysektomie auf die Funktion und Morphologie der Dünndarmschleimhaut der Ratte. Verhandl. dtsch. Ges. inn. Med., 78, 1432-1434. 
MENGE H., GRAFE M., LORENZ MEYER H., RIECKEN E. O., 1975a. The influence of food intake on the development of structural and functional adaptation following ileal resection in the Rat. Gut, 16, 468-472.

MENGE H., ROBINSON J. W. L., 1978. Functional and structural characteristics of the rat intestinal mucosa following ileo-jejunal transposition. Acta hepatogast., 25, 150-154.

MENGE H., ROBINSON J. W. L., 1979. Early phase of jejunal regeneration after short term ischemia in the rat. Lab. Invest., 40, 25-30.

MENGE H., WERNER H., LORENZ-MEYER H., RIECKEN E. O., 1975b. The nutritive effect of glucose on the structure and function of jejunal self-emptying blind loops in the rat. Gut, 16, $462-467$.

MESLIN J. C., SACQUET E., GUENET J. L., 1973. Action de la flore bactérienne sur la morphologie et la surface de la muqueuse de l'intestin grêle du rat. Ann. Biol. anim. Bioch. Biophys., 13, 203-214.

MIAZZA B. M., GHATEI M. A., ADRIAN T. E., BLOOM S. R., DOWLING R. H., 1982a. Are hormonal factors responsible for the intestinal and pancreatic hyperplasia of pancreatico biliary diversion (PBD) ? Regul. Peptides, 3, 77 (abstr.).

MIAZZA B. M., LEVAN VAN HUNG, VAJA S., DOWLING R. H., 1982b. Effect of pancreaticobiliary diversion (PBD) on jejunal and ileal structure and function in the rat, 467-476. In ROBINSON J. W. L., DOWLING R. H., RIECKEN E. O., Mechanisms of intestinal adaptation, MTP Press Ltd, Lancaster.

MIAZZA B. M., LEVAN VAN HUNG, VAJA S., DOWLING R. H., 1982c. Pancreatic hyperplasia after pancreatico-biliary diversion (PBD) in orally- and parenterally-fed rats, 481-490. In ROBINSON J. W. L., DOWLING R. H., RIECKEN E. O., Mechanisms of intestinal adaptation, MTP Press Ltd, Lancaster.

MILLER D. L., HANSON W., SCHEDL H. P., OSBORNE J. W., 1977. Proliferation rate and transit time of mucosal cells in small intestine of the diabetic rat. Gastroenterology, 73, 1326-1332.

MISSEN A. J. B., 1976. The effect of vagotomy on the enteric plexuses. Med. Sci. Aliment. Sys., 4, 257.

MOOLTEN F. L., BUCHER N. L. R., 1967. Regeneration of rat liver : transfer of humoral agent by cross-circulation. Science, 158, 272-274.

MOOSSA A. R., HALL A. W., SKINNER D. B., WINANS C. S., 1976. Effect of fifty percent small bowel resection on gastric secretory function in Rhesus monkeys. Surgery, 80, 208-213.

MORIN C. L., GREY V. L., GAROFALO C., 1982. Influence of lipids on intestinal adaptation after resection, 175-184. In ROBINSON J. W. L., DOWLING R. H., RIECKEN E. O., Mechanisms of intestinal adaptation, MTP Press Ltd, Lancaster.

MORIN C. L., LING V., 1978. Effect of pentagastrin on the rat small intestine after resection. Gastroenterology, 75, 224-229.

MORIN C. L., LING V., VAN CAILLIE M., 1978. Role of oral intake on intestinal adaptation after small bowel resection in growing rats. Pediatr, Res., 12, 268-271.

MUNDAY E. M. D., MUNDAY K. A., POAT J. A., 1982. Cell kinetics in the mucosal epithelium of the jejunum of normal, adrenalectomized and salt-loaded rats, 55-64. In ROBINSON J. W. L., DOWLING R. H., RIECKEN E. O., Mechanisms of intestinal adaptation, MTP Press Ltd, Lancaster.

MUSSO F., LACHAT J. J., CRUZ A. R., GONÇALVES R. P., 1975. Effect of denervation on the mitotic index of the intestinal epithelium of the rat. Cell Tissue Res., 163, 395-402.

NAKAYAMA H., IJU M., NAKAGAWA S., 1974. Influence of diet on intestinal cell DNA synthesis in the diabetic rat. Diabetes, 23, 793-795.

OBERTOP H., NUNDY J., MALAMUD D., MALT R. A., 1977. Onset of cell proliferation in the shortened gut : rapid hyperplasia after jejunal resection. Gastroenterology, 72, 267-270.

OSCARSON J. E. A., VEEN H. F., WILLIAMSON R. C. N., ROSS J. S., MALT R. A., 1977. Compensatory postresectional hyperplasia and starvation atrophy in small bowel : dissociation from endogenous gastrin levels. Gastroenterology, 72, 890-895.

PANSU D., BERARD A., DECHELETTE M. A., LAMBERT R., 1974 . Influence of secretin and pentagastrin on the circadian rhythm of cell proliferation in the intestinal mucosa in rats. Digestion, 11, 266-274. 
PANSU D., BERARD A., LAMBERT R., 1977. Régulation du renouvellement cellulaire dans la muqueuse gastrointestinale. Path. Biol., 25, 119-133.

PARHON C. C., PETCU G., BRINZOIU M., 1978. The influence of partial resection of the small intestine on the pituitary gland. Rev. roum. Morphol. Embryol. Physiol. (Physiol.), 15, 97-100.

PETERSEN H., SOLOMON T., GROSSMAN M. I., 1978. Effect of chronic pentagastrin, cholecystokinin and secretin on pancreas of rats. Am. J. Physiol., 234, E286-E293.

PISHVA N., MANN M., ABTAHI F. S., DJAHANGUIRI B., 1975. Decreased mitotic activity in the stomach, duodenum and colon of rats treated with high doses of histamine. Pharmacology, 13, 1-4.

POLAK J. M., FERRI G. L., HARRIS A., BUCHAN A. M. J., KOOPMANS H. S, GREGOR M., GHATEI M. A., BLOOM S. R., WRIGHT N. A., 1982. Dynamics of the enteroglucagon cell during intestinal adaptation, 257-265. In ROBINSON J. W. L., DOWLING R. H., RIECKEN E. O., Mechanisms of intestinal adaptation, MTP Press Ltd, Lancaster.

POTTEN C. S., HENDRY J. H., 1975 . Differential regeneration of intestinal proliferative cells and cryptogenic cells after irradiation. Int. J. Radiat. Biol., 27, 413-424.

POULAKAS L., OSBORNE J. W., 1973. The kinetics of cellular recovery in locally X-irradiated rat ileum. Radiat. Res., 53, 402-413.

RÄSANEN T., 1963. Fluctuations in the mitotic frequency of the glandular stomach and intestine of rat under the influence of $\mathrm{ACTH}$, glucocorticoids, stress and heparin. Acta physiol. scand., 58, 201-210.

RIJKE R. P. C., HANSON W. R., PLAISIER H. M., 1977. The effect of transposition to jejunum on epithelial cell kinetics in an ileal segment. Cell. Tissue. Kinet., 10, 399-406.

RIJKE R. P. C., HANSON W. R., PLAISIER H. M., OSBORNE J. W., 1976. The effect of ischemic villus cell damage on crypt cell proliferation in the small intestine; evidence for a feedback control mechanism. Gastroenterology, 71, 786-792.

RIJKE R. P. C., MEER-FIEGGEN W. Van Der, GALJAARD H., 1974. Effect of villus length on cell proliferation and migration in small intestinal epithelium. Cell Tissue Kinet., 7, 577586.

RIJKe R. P. C., PLAISIER H., hOOgeVEen A. T., LAMERTON L. F., GALJAARD H., 1975. The effect of continuous irradiation on cell proliferation and maturation in small intestinal epithelium. Cell Tissue Kinet., 8, 441-453.

RIJKE R. P. C., PLAISIER H. M., RUITER H. de, GALJAARD H., 1977. Influence of experimental bypass on cellular kinetics and maturation of small intestinal epithelium in the rat. Gastroenterology, 72, 896-901.

ROY C. C., LAURENDEAU G., DOYON G., CHARTRAND L., RIVEST M. R., 1975. The effect of bile and of sodium taurocholate on the epithelial cell dynamics of the rat small intestine. Proc. Soc. exp. Biol. Med., 149, 1000-1004.

RUDO N. D., ROSENBERG I. H., WISSLER R. W., 1976. The effect of partial starvation and glucagon treatment of intestinal villus morphology and cell migration. Proc. Soc. exp. Biol. Med., 152, 277-280.

SAGOR G. R., AL-MUKHTAR M. Y. T., GHATEI M. A., WRIGHT N. A., BLOOM S. R., 1982. The effect of altered luminal nutrition on cellular proliferation and plasma concentrations of enteroglucagon and gastrin after small bowel resection in the rat. Br. J. Surg., 69, 14-18.

SASSIER P., BERGERON M., 1977. Specific inhibition of cell proliferation in the mouse intestine by an aqueous extract of rabbit small intestine. Cell. Tissue Kinet., 10, 223-231.

SASSIER P., BERGERON M., 1978. Cellular changes in the small intestine epithelium in the course of cell proliferation and maturation. Sub-cell. Biochem. 5, 129-185.

SCHOFIELD G. C., 1960. Experimental studies on the innervation of the mucous membrane of the gut. Brain, 83, 490-515.

SCOTT J., BATT R. M., PETERS T. J., 1979. Enhancement of ileal adaptation by prednisolone after proximal small bowel resection in the rat. Gut, 20, 858-864.

SCOTT J., PETERS T. J., 1982. Adaptive response of the gastro-intestinal tract to corticosteroids with special reference to the effects of pharmacological doses of prednisolone on the small intestine, 299-306. In ROBINSON J. W. L., DOWLING R. H., RIECKEN E. O., Mechanisms of intestinal adaptation. MTP Press Ltd, Lancaster. 
SENEGAS-BALAS F., BALAS D., BOUISSON M., RIBET A., 1981. Effect of pancreatic duct ligation on the hamster intestinal mucosa. Variation of several hydrolases. Digestion, 21, 8391.

SENIOR P. V. PRITCHETT C. J., SUNTER J. P., APPLETON D. R., WATSON A. J., 1982. Stathmokinetic studies on intestinal crypts following $70 \%$ resection of the small bowel or transplantation of $10-20 \mathrm{~mm}$ of small bowel to the exterior abdominal wall, 337-351. In ROBINSON J. W. L., DOWLING R. H., RIECKEN E. O., Mechanisms of intestinal adaptation. MTP Press Ltd, Lancaster.

SHARP J. G., OSBORNE J. W., 1981. Evidence against a systemic humoral factor controlling the intestinal compensatory response following $X$-irradiation. Virchows Arch., 37B, 71-78.

SHELLITO P. C., DAHL E. P., TERPSTRA O. T., MALT R. A., 1978. Postresectional hyperplasia of the small intestine without bile and pancreatic juice. Proc. Soc. exp. Biol. Med., 158, 101-104.

SHIMODA S. S., SAUNDERS D. R., RUBIN C. E., 1968. The Zollinger-Ellison syndrome with steatorrhea. 2) The mechanisms of fat and vitamin $B_{12}$ malabsorption. Gastroenterology, 55, 705-723.

SILEN W., PELOSO O., JAFFE B. F., 1966. Kinetics of intestinal epithelial proliferation ; effect of vagotomy. Surgery. 60, 127-135.

SMYTH D. H., 1962. Glucose absorption. Gastroenterology, 42, 76-79.

SPECTOR M. H., LEVINE G. M., DEREN J. J., 1977. Direct and indirect effects of dextrose and amino acids on gut mass. Gastroenterology, 72, 706-710.

SPRINZ H., 1971. Factors influencing intestinal cell renewal: a statement of principles. Cancer, 28, 71-74.

STEINER M., BOURGES H. R., FREEDMAN L. S., GRAY S. J., 1968. Effect of starvation on the tissue composition of the small intestine in the rat. Amer. J. Physiol., 215, 75-77.

STRAUS E., GERSON C. D., YALOW R. S., 1974. Hypersecretion of gastrin associated with the short bowel syndrome. Gastroenterology, 66, 175-180.

SVENBERG T., CHRISTOFIDES N. D., FITZPATRICK M. L., BLOOM S. R., WELBOURN R. B., 1982. Plasma motilin and biliary output in man. Clin. Sci, 62, 20-21 P (abstr. $n^{\circ} 59$ ).

SYME G., HUSAIN R., 1982. The structural and functional adaptation of rat mid-jejunum to protein deficiency, 111-119. In ROBINSON J. W. L., DOWLING R. H., RIECKEN E. O., Mechanisms of intestinal adaptation. MTP Press Ltd, Lancaster.

TAYLOR B., MURPHY G. M., DOWLING R. H., 1975. Influence of pituitary hormones on intestinal structure and function after small bowel resection in the rat. Gastroenterology, 68, 887 (Abstr.).

TAYLOR B., MURPHY G. M., DOWLING R. H., 1979. Pituitary hormones and the small bowel : Effect of hypophysectomy on intestinal adaptation to small bowel resection. Eur. J. clin. Invest., 9, 115-127.

TILSON M. D., 1972. Compensatory hypertrophy of the gut: Testing on the tissue mass, intraluminal nutrition and functional demand hypothesis. Arch. Surg., 104, 69-72.

TILSON M. D., AXTMAYER A., 1976. Antral exclusion enhances compensatory hypertrophy of the gut after partial enterectomy. J. Surg. Res., 20, 275-279.

TILSON M. D., CLEVELAND J. C., WRIGHT H. K., 1969. A similar effect of jejunectomy on ileal mucosa in bypassed and normal ileum. Surg. Forum, 20, 401-402.

TILSON M. D., LIVSTONE E. M., 1975. Radioautography of heterotopic autografts of ileal mucosa in rats after partial enterectomy. Surg. Forum, 26, 393-394.

TILSON M. D., PHILLIPS S., WRIGHT H. K., 1971. An effect of deoxycorticosterone upon the ileum simulating compensatory hypertrophy of the gut. Surgery, 69, 730-735.

TILSON M. D., SWEENEY T., WRIGHT H. K., 1975. Compensatory hypertrophy of the ileum after gastroduodenojejunal exclusion. Arch. Surg., 110, 309-312.

TILSON M. D., WALTON R., LIVSTONE E. M., 1975. Starvation overrides humoral stimuli for adaptive growth of the ileum in parabiotic rats. Clin. Res., 23, 579 (abstr.).

TILSON M. D., WRIGHT H. K., 1970. Adaptation of functioning and bypassed segments of ileum during compensatory hypertrophy of the gut. Surgery, 67, 687-693.

TILSON M. D., WRIGHT H. K., 1971. Villus hyperplasia in parabiotic rats. Clin. Res., 19, 405 (abstr.). 
TOULOUKIAN R. J., MITRUKA B., HOYLE C., 1971. Growth and nutrition of enterectomized rats fed an elemental liquid diet. Surgery, 69, 637-645.

TOULOUKIAN R. J., TILSON M. D., ROTH R., 1975. Effects of pharmacologic sympathectomy on gut hypertrophy in enterectomized rats. J. Surg. Res., 19, 9-11.

TRENDELENBURG U., 1963. Supersensitivity and subsensitivity to sympathomimetic amines. Pharmacol. Rev., 15, 225-276.

TUTTON P. J. M., 1973a. Control of epithelial cell proliferation in the small intestinal crypt. Cell Tissue Kinet., 6, 211-216.

TUTTON P. J. M., 1973b. Proliferation of epithelial cells in the jejunal crypts of adrenalectomized and adrenocortical hormone treated rats. Virchows Arch., 13B, 227-232.

TUTTON P. J. M., 1974. The influence of serotonin on crypt cell proliferation in the jejunum of rat. Virchows Arch., 16B, 79-87.

TUTTON P. J. M., 1975a. Neural stimulation of mitotic activity in the crypts of Lieberkühn in rat jejunum. Cell Tissue Kinet., 8, 259-266.

TUTTON P. J. M., 1975b. The influence of cholinoceptor activity on the mitotic rate in the crypts of Lieberkühn in rat jejunum. Clin. exp. Physiol. Pharmacol., 2, 269-276.

TUTTON P. J. M., 1976. The influence of histamine on epithelial cell proliferation in the jejunum of rat. Clin exp. Physiol. Pharmacol., 3, 369-373.

TUTTON P. J. M., 1977. Neural and endocrine control systems acting on the population kinetics of the intestinal epithelium. Med. Biol., 55, 201-208.

TUTTON P. J. M., HELME R. D., 1974. The influence of adrenoceptor activity on crypt cell proliferation in the rat jejunum. Cell Tissue Kinet., 7, 125-136.

UTTENTHAL L. O., BATT R. M., CARTER M. W., BLOOM S. R., 1982. Stimulation of DNA synthesis in cultured small intestine by partially purified enteroglucagon. Regul. Peptides, 3, 84 (abstr.).

UVNÄS-WALLENSTEN K., 1977. Occurrence of gastrin in gastric juice, in antral secretion, and in antral perfusates of cats. Gastroenterology, 73, 487-491.

UVNÄS-WALLENSTEN K., EFENDIC S., 1978. Release of gastro intestinal hormones into the duodenal lumen of cats. Horm. Metab. Res., 10, 173-174.

UVNÄS-WALLENSTEN K., EFENDIC S., JOHANSSON C., SJÖDIN L., CRANWELL P.D., 1980. Effect of intraluminal $\mathrm{pH}$ on the release of somatostatin and gastrin into antral, bulbar and ileal pouches of conscious dogs. Acta physiol. scand., 110, 391-400.

VENZA-TETI D., 1974. Effect of ovariectomy on tritiated thymidine incorporation into DNA of " non target " organs of the mouse. Hormone Res., 5, 187-192.

WAGNER R., 1980. Ischämische Schadigung und postischämische Regeneration der Dünndarmschleimhaut. Fortschr. Med., 98, 1077-1082.

WATHEN L. M., OSBORNE J. W., LOVEN D. P., 1981. Effect of two intestinal resections separated by time on cell proliferation in the rat small intestine. Gastroenterology, 80, 15351541.

WEISS P., KAVANAU J. L., 1957. A model of growth and growth control in mathematical terms. J. Gen. Physiol., 41, 1-47.

WESER E., 1979. Nutritional aspects of malabsorption. Am. J. Med., 67, 1014-1020.

WESER E., HELLER R., TAWIL T., 1977. Stimulation of mucosal growth in the rat ileum by bile and pancreatic secretions after jejunal resection. Gastroenterology, 73, 524-529.

WESER E., TAWIL T., 1978. Intravenous cholecystokinin (CCK) stimulates growth of ileal mucosa after jejunectomy in parenterally nourished rats. Gastroenterology, 74, 1111 (abstr.).

WESER E., TAWIL T., FLETCHER J. T., 1982. Stimulation of small bowel mucosal growth by gastric infusion of different sugars in rats maintained on total parenteral nutrition, 141-149. In ROBINSON J. W. L., DOWLING R. H., RIECKEN E. O., Mechanisms of intestinal adaptation. MTP Press Ltd, Lancaster.

WESER E., VANDEVENTER A., TAWIL T., 1982. Non-hormonal regulation of intestinal adaptation, 105-113. In POLAK J. M., BLOOM S. R., WRIGHT N. A., DALY M. J., Adaptation pathophysiology of intestinal response to disease. Scand. J. Gastroenterol., 17, suppl. 74.

WILLIAMSON R. C. N., 1978a. Intestinal adaptation. 1) Structural, functional and cytokinetic changes. New-Engl. J. Med., 298, 1393-1402. 
WILLIAMSON R. C. N., 1978b. Intestinal adaptation. 2) Mechanisms of control. New-Engl. J. Med., 298, 1444-1450.

WILLIAMSON R. C. N., BAUER F. L. R., 1978. Evidence for an enterotropic hormonc: compensatory hyperplasia in defunctioned bowel. Br. J. Surg., 65, 736-739.

WILLIAMSON R. C. N., BAUER F. L., ROSS J. S., MALT R. A., 1978a. Proximal enterectomy stimulates distal hyperplasia more than bypass or pancreatico-biliary diversion. Gastroenterologv, 74, 16-23.

WILLIAMSON R. C. N., BAUER F. L. R., ROSS J. S., MALT R. A., 1978b. Contributions of bile and pancreatic juice to cell proliferation in ileal mucosa. Surgery, 83, 570-576.

WILLIAMSON R. C. N., BUCHHOLTZ T. W., MALT R. A., 1978. Humoral stimulation of cell proliferation in small bowel after transection and resection in rats. Gastroenterology, 75 , 249-254.

WILLIAMSON R. C. N., MALT R. A., 1982. Humoral modulation of compensatory intestinal hyperplasia, 215-224. In ROBINSON J. W. L., DOWLING R. H., RIECKEN E. O., Mechanisms of intestinal adaptation. MTP Press Ltd, London.

WISEMAN D. A., JOHNSON L. R., 1976. Evidence that secretin does not have direct antitrophic effects on the rat stomach. Proc. Soc. exp. Biol. Med., 153, 277-279.

WRIGHT H. K., CLEVELAND J. C., TILSON M. D., HERSKOVIC T., 1969. Morphology and absorptive capacity of the ileum after ileostomy in man. Am. J. Surg., 117, 242-244.

WRIGHT N. A., MORLEY A. R., APPLETON D., 1972. The effect of testosterone on cell proliferation and differentiation in the small bowel. $J$. Endocrinol., 52, 161-175.

YEH K., 1977. Cell kinetics in the small intestine of suckling rats. 1). Influence of hypophysectomy. Anat. Rec., 188, 69-76.

YEH K. Y., MOOG F., 1978. Hormonal influences on the growth and enzymic differentiation of the small intestine of the hypophysectomized rat. Growth, 42, 495-504. 